\title{
Association of road traffic noise exposure and prevalence of coronary artery disease: A cross-sectional study in North India
}

\author{
Towseef Ahmed Gilani ${ }^{1}$ (D) Mohammad Shafi Mir ${ }^{2}$ (D) \\ Received: 25 December 2020 / Accepted: 21 May 2021 / Published online: 24 May 2021 \\ (C) The Author(s), under exclusive licence to Springer-Verlag GmbH Germany, part of Springer Nature 2021
}

\begin{abstract}
Epidemiological studies have established that noise from transportation sources exceeding the safe limits elevates the risk for cardiovascular diseases. The results however have remained heterogeneous. The present study was conducted to investigate the association between road traffic noise exposure and prevalence of coronary artery disease besides sub-group analysis was performed for identifying the most susceptible population. Traffic noise exposure was measured using the $\mathrm{L}_{\mathrm{den}}$ metric in both continuous and categorical forms. A cross-sectional study was performed and information about sociodemographic, lifestyle, and health-related factors was collected. Noise level $<60 \mathrm{~dB}(\mathrm{~A})$ representing the quiet areas was used as the reference group. Univariate and multivariate logistic regressions were performed to estimate the odds for self-reported coronary artery disease concerning road traffic noise after adjusting for confounding variables. The residents living in noisy areas were found to have a 2.25 times higher risk per $5 \mathrm{~dB}(\mathrm{~A})$ increment in the noise levels $(95 \% \mathrm{CI}=1.38$ to 3.67). Males were at a higher risk of CAD (OR $=2.61 ; 95 \% \mathrm{CI}=1.84$ to 3.72$)$ as compared to females $(\mathrm{OR}=2.07 ; 95 \% \mathrm{CI}=1.37-3.13)$. The subgroup analysis revealed that being sensitive to noise, belonging to a higher age group, reporting higher stress levels, and poor sleep quality were associated with higher risk. The study also provides evidence that exposure to noise levels greater than $60 \mathrm{~dB}(\mathrm{~A})$ is associated with the prevalence of coronary artery disease in adults.
\end{abstract}

Keywords Coronary artery disease $\cdot$ Risk factors $\cdot$ Directed acyclic graph $\cdot$ Sleep quality $\cdot$ Stress level $\cdot$ Traffic noise

\section{Introduction}

Transportation noise was identified as a significant source of concern in the European Commission's green paper on future noise policy, which included the development of safe limit criteria. Traffic noise is considered to be the second-worst environmental stressor that affects human health, surpassed only by air pollution. As per WHO (World Health Organization), the number of healthy life years lost, expressed as DALY (disability-adjusted life years), due to traffic noise

Responsible Editor: Lotfi Aleya

Towseef Ahmed Gilani tawseef_46phd15@nitsri.ac.in

1 Department of Civil Engineering, National Institute of Technology, Srinagar, J\&K 190006, India

2 Transportation \& Planning Section, Department of Civil Engineering, National Institute of Technology, Srinagar, J\&K 190006, India exceeds 1 million per year in European countries, with CVD (cardiovascular diseases) accounting for more than 61,000 years, sleep disturbance accounting for 9,03,000 years, and annoyance accounting for 6,54,000 years (WHO 2011). The growing volume of evidence indicates that traffic noise may also prove to be a significant risk factor for other health effects like diabetes (Zare Sakhvidi et al. 2018) and stroke (Sorensen et al. 2011) which will result in a substantial increase in DALY estimates. The past few decades have seen a considerable change in the spectrum of diseases resulting in an increase in the share of non-communicable diseases like CVD in the overall global burden of disease (Cohen et al. 2017). Chronic exposure to noise levels greater than $55 \mathrm{~dB}(\mathrm{~A})$ has shown to result in an increase in blood pressure, change of respiration and heart rate, suppression of the central nervous system, mental disorders, hypertension, diabetes, and even interruptions in metabolism (Munzel et al. 2014; Brown 2015). Studies have reported road traffic noise being associated with cardiovascular morbidity and mortality (Babisch 2011; Munzel et al. 2014). However, the growing body of evidence has not been able to garner enough attention as 
compared to other environmental issues like air and water pollution even though noise pollution is considered to be the main reason for the declining quality of life (Bluhm et al. 2019). The reasons for attaching lower priority to traffic noise by the decision-makers can be due to the less awareness about the problems or less familiarity with those effects of noise which are unspectacular as noise is insidious and not catastrophic. As far as the general population is considered, attaching lower priority to noise can be because noise is very much a localized problem with different effects on the population. Despite these reasons, a general international consensus has been reached regarding the unacceptable level of noise to which people should not be subjected to protect health and quality of life.

\section{Effects of noise based on gender, age, and noise levels}

Early studies conducted by Barregard et al. (Barregard et al. 2009) revealed that modeled traffic noise levels were significantly associated with the prevalence of hypertension especially for the male population with a residence period of more than 10 years. The association was not significant for the female population. However, another study carried out in Sweden revealed that there were no significant differences based on gender for the association between the prevalence of CVD and traffic noise (Bodin et al. 2009). The study revealed that effects were significant for middle-aged (40-59 years) population as compared to young (18-39 years) and old aged (60-80 years) population. A study conducted in six European nations i.e., England, Italy, Sweden, Germany, the Netherlands, and Greece, found that exposure to average daily traffic noise levels was having a significant association for CVD especially for men (Jarup et al. 2008). The study further revealed that the risks increased with the increasing traffic noise levels. In a study conducted in the USA, exposure to traffic noise was associated with an increased prevalence of CAD (coronary artery disease) among men aged less than 50 years (Gan et al. 2011). A study conducted in Madrid, Spain, found that exposure to increasing noise levels can significantly increase the risk for cardiovascular mortality especially in people aged more than 65 years (Tobías et al. 2015). The study also found that road traffic noise was the most significant contributor to the overall environmental noise levels, with a contribution of nearly $80 \%$. Two community-based studies have revealed that exposure to road traffic noise levels (expressed in terms of 24-h average values) greater than 55 $\mathrm{dB}(\mathrm{A})$ can cause cardiovascular diseases in populations aged more than 45 years. However, both studies differed in their outcomes based on gender differences with one of the studies reporting significant association for women and another reporting no difference between the two (Leon Bluhm et al. 2006; de Kluizenaar et al. 2007). Another study carried out in
China revealed that exposure to traffic noise was a significant risk factor for the development of cardiovascular diseases in people aged (18-32) years with females being at higher risk (Chang et al. 2009).

CVD has turned out to be the leading cause of mortality in India (Srinath Reddy et al. 2005). In comparison to the European population where only $23 \%$ of the mortality due to CVD occurs before the age of 70 years, in the Indian population, nearly $52 \%$ of the mortality cases due to CVD occur before the age of 70 years (Rashid and Khandaker 2007). The past 20 years have witnessed a significant epidemiological transition in India with non-communicable diseases becoming more prevalent. This has been partly due to the efforts in curbing infectious diseases thereby increasing the life expectancy from 58.3 to 65.2 years and increasing the aged population in the country during the same period. Consequently, the burden of non-communicable diseases also increased with a proportional increase in burden due to CVD (IHME 2010).

\section{Pathophysiology associated with cardiovascular diseases due to noise exposure}

As per the model proposed by Babisch (2003), an indirect pathway leads to the development of CVD due to exposure to environmental noise even at lower levels. The pathway consists of disturbances in sleep, communication, and daily activities followed by emotional and cognitive responses and annoyance. This leads to a chronic stress reaction which causes pathophysiological alterations in the immediate or chronic timeframe thereby leading to adverse health outcomes. Additionally, chronic stress can also lead to the development of established cardiovascular risk factors like blood pressure, high blood sugar levels, high blood viscosity, and activation of blood clotting of its own, which can result in CVD. The annoyance induced by traffic noise exposure is an important moderator of the relationship between noise and cardiovascular disease like hypertension and CAD (Babisch et al. 2003). Besides exposure to environmental noise has also been found to cause mental health issues like anxiety and depression (Beutel et al. 2016) which have been found to adversely affect cardiovascular health.

The explanation regarding the effects of noise on the cardiovascular system based on molecular mechanisms is not fully understood. The proposed mechanism states that activation of the autonomic nervous system and elevated levels of stress hormones like cortisol (Babisch 2003; Babisch 2006, 2011; Babisch and van Kamp 2009) can lead to endothelial dysfunction via the initiation of oxidative stress (Schmidt et al. 2013, 2015) followed by clotting of blood (thrombophilia) and vascular inflammation (Charakida and Deanfield 2013). In addition to endothelial dysfunction, high blood pressure, 
hyperlipidemia, fluctuations in the blood glucose levels, and change in HRV (heart rate variability) due to stress hormones can play an important role in the development of CVD and its progression. The vascular dysfunction due to noise exposure is of higher significance for individuals who have an established CAD. Higher cortisol levels also lead to hyperglycemia through reduced insulin sensitivity (Aronson and Rayfield 2002) and elevated levels of ghrelin hormone and lower levels of leptin hormone (Chao et al. 2017) and both these factors can cause cardiovascular problems including $\mathrm{CAD}$, atherosclerosis, myocardial infarction, and ischemic heart disease.

Another mechanism explaining the role of traffic noise in causing CVDs is sleep disturbances (Babisch 2014; Basner et al. 2014). Traffic noise during the night can lead to sleep fragmentation and sleep restriction which has been found to exert negative impacts on various systems including metabolic and endocrine systems. Acute and chronic sleep restriction or fragmentation can cause inadequate secretion of insulin, reduction of insulin sensitivity, and dysfunction of the arterial and venous endothelial system. Reduced sleep both in terms of quality and duration can lead to coronary artery calcification which ultimately leads to CAD (Münzel et al. 2018, 2019). The role of nocturnal traffic noise becomes even more important because cardiovascular responses to road traffic noise are observed with no or very little signs of habituation (Carter et al. 2002; Griefahn et al. 2008). Thus, long-term exposures to nocturnal traffic noise can lead to dysregulation and irreversible physiological changes that lead to an increase in the risk of cardiovascular diseases. One such study conducted in Germany also found that nocturnal traffic noise was independently associated with the development of atherosclerosis and that being more close to the traffic increases the risk (Kalsch et al. 2014). A systematic review of the available literature concerning the impact of traffic noise on various cardiometabolic systems was performed to update the WHO environmental noise guidelines for the European region. The study points towards the development of stress, reduction of sleep quality, and sleep duration to be the most significant paths responsible for negative cardiovascular outcomes (van Kempen et al. 2018).

\section{Urban morphology of Indian cities}

Most of the Indian cities have a long history of development comprising of both pre-independence and post-independence periods. Indian cities present a mix of both these periods. Some of the specific features of Indian cities include:

a) Improper delineation of residential and commercial areas: In most Indian cities, residential areas are mixed with commercial areas and located in the core of the city known as CBD (central business district). In addition to this commercial areas have encroached on residential areas. Sometimes the development of new residential areas is coupled with the growth of commercial areas along roads or even within the residential buildings or complex.

b) Unplanned growth of functional areas: Most of the cities have a history of unplanned growth thereby resulting in the mixing of various functional areas. However, newly developed areas have come up as per proper planning norms.

c) No segregation of residential zones based on economic class: Most Indian cities have residential zones comprising of people from all sorts of economic backgrounds. Although the middle or upper class tends to relocate towards the periphery regions, a considerable number of lower-income class dwellings have also come up.

d) Less suburban growth: The feasibility of suburban areas depends upon the availability of wide roads, cheap and fast means of transportation. However, only a few Indian cities like Mumbai, Delhi, and Kolkata have seen the growth of suburban areas due to the availability of metro, local trains, and robust transport bus services.

e) Irregular population density: Indian cities have witnessed a sharp decline in the population density from the inner core of the city towards the periphery. This is due to the tendency to reside near the facilities like markets, hospitals, and places of work. The peripheral areas are generally preferred by those with their means of transportation so that they can easily undertake trips from home to other places of interest.

\section{Acoustical environment of Indian cities}

Studies conducted across various cities of India witnessed high environmental noise levels ranging from 70.1 to 120.4 $\mathrm{dB}(\mathrm{A})$. A major contribution to such high noise levels comes from road traffic (Banerjee et al. 2008). The noise levels emitted from vehicles often exceed the permissible values (Goswami et al. 2011). The vehicular noise forming a major component of environmental noise is characterized by frequent honking. Studies have reported higher noise levels being reported from silence zones and lowest for residential areas. However, the maximum and minimum noise levels for silence and residential zones were above the permissible levels as prescribed by CPCB (Central Pollution Control Board). Continuous growth in population, transportation demand, increase in the vehicle population, and frequent congestion on roads intensify the noise levels. Exposure to such high noise levels can result in various negative health effects. 
Improper planning regarding the layout of roads and highways is often found to result in residential, commercial, and industrial areas lying close to one another. A study carried out in West Bengal, India, revealed noise levels up to $90 \mathrm{~dB}(\mathrm{~A})$ around silence zones due to improper layout of roads (Datta et al. 2006). Studies have found residents considering traffic noise to be most disturbing and often resulting in headache, dizziness, high blood pressure, and fatigue (Pathak et al. 2008). WHO has listed several critical health issues due to exposure to traffic noise at different time settings (Berglund and Lindvall n.d.).

\section{Traffic scenario of Indian cities}

One of the main aspects of the economic growth of Asian countries is rapid urbanization. According to the Asian development bank, 44 million people are being added annually to the urban population of Asia. With such an increase, there has been an increase in the demand for mobility and a consequent increase in vehicle ownership. As per Census 2011, India's urban population increased from 290 million in 2001 to 377 million in 2011, which accounts for a $30 \%$ increase in the total population. The significant increase in the vehicle population has overwhelmed the available traffic infrastructure resulting in various problems including air pollution, noise pollution, congestion, higher travel time, reduced traffic speed, and high vehicle ownership cost. The heterogeneous traffic conditions prevalent in urban areas include private cars, buses, trains, trucks, auto-rickshaws, and animal-driven carts. The average journey speed in the national capital is around $16 \mathrm{kmph}$ while it is slightly higher in Mumbai, the financial capital of India. The growth in vehicular population is more than the growth of population in most of the Indian cities, and the annual growth generally ranges from 15 to $20 \%$ (Reddy and Balachandra 2010). As the urban population utilizes different transportation modes for undertaking daily journeys, the modal choice is influenced by a various set of factors comprising mainly of social, economic, physical, and human. Even though the public transport system offers strong competition, its market share has shown a continuous decline. There is a gradual shift from public transport towards private transport (Pucher et al. 2005). Usage of two-wheelers and private cars are the most preferred, while walking and bicycles, which were once an important means of mobility, have taken a back seat. Motorcycles and private cars are generally preferred by people in the age group of 20 to 35 years, which forms nearly $60 \%$ of the population (Reddy and Balachandra 2010). The increasing usage of private means of transportation is an important factor that directly relates to the degradation of environmental quality and higher energy utilization. The problem that policymakers are facing is: whether policies should focus on accommodating the growing levels of personal transport or should the policies be focused towards discouraging the excessive use of personal transport so that degradation of environmental quality and other negative externalities could be reduced? The solution to this problem could be the improvement of the public transport system and also providing improvement in the quality of transit, walking, and bicycling, by increasing accessibility (Reddy and Balachandra 2010). The urban morphology characteristics, acoustical quality, and traffic scenario prevalent in most of the cities in India lead to higher noise exposure for the resident population and thus can account for various negative health effects including both auditory and non-auditory effects. Studies focusing on identifying the risk factors and quantifying the risks are therefore highly recommended by epidemiologists and concerned authorities so as to minimize such effects.

\section{Noise maps and facade maps}

Traffic noise is one of the major sources of environmental noise in both developed and developing urban areas which makes an accurate and effective assessment of traffic noise exposure important for decision-making authorities in these urban areas. Noise maps are the most sophisticated means of visualizing and understanding environmental noise. Some of the important usages include:

(1) Illustrating the environmental noise exposure which can serve as a reference for decision-makers.

(2) Quantification of the noise exposure level.

(3) To devise policies for controlling noise and also to enforce noise control measures.

(4) It can prove helpful in devising a cost-benefit plan and thus governments desiring to reduce noise levels.

(5) It can also help in monitoring the noise attenuation schemes and their effectiveness during the implementation process.

(6) It also helps in providing a research platform for undertaking studies focusing on the influence of noise levels on the human body.

In addition to visualizing the acoustic environment of a given area, noise maps also help in developing relations between noise levels and traffic characteristics like traffic speed, traffic composition, and road characteristics like type of material used and the width of pavement. However, the noise levels reaching facades of the different urban buildings may not be the same as that of the surrounding noise levels, due to various factors like ground attenuation, atmospheric attenuation, and attenuation due to other surrounding buildings. Therefore, facade maps are developed for depicting the noise levels reaching the facades of the buildings. This also helps in calculating the 
number of individuals exposed to different noise levels (Ko et al. 2011).

\section{Need for the study}

Although review studies concerned with the association of road traffic noise and CVD have established the association, the epidemiological evidence has remained heterogeneous and inconclusive (Belojevic et al. 2011; Davies and Van Kamp 2012). The available literature and studies reporting the association between road traffic noise and CVD have remained limited to the developed world, whereas there is a scarcity of such research from developing countries in general and India in particular. During the literature review, it was also found that the susceptibility to effects of road traffic noise based on gender, age, and noise levels has remained heterogeneous. Therefore, this study was conducted to establish the association of road traffic noise with the prevalence of CAD. However, the literature review revealed that higher traffic noise levels were presenting a higher risk for the prevalence and incidence of CVD. Therefore, it was hypothesized that the prevalence of CAD would be high in areas exposed to traffic noise levels greater than $60 \mathrm{~dB}(\mathrm{~A})$.

\section{Primary objective}

1. To evaluate the direct association of road traffic noise with the prevalence of coronary artery disease among adults

\section{Secondary objectives}

1. To find the most susceptible population in terms of age group, lifestyle, and sociodemographic characteristics for the development of CAD due to road traffic noise

2. To determine the threshold value of traffic noise beyond which there is a significant increase in the risk of CAD

\section{Methods}

\section{Sample size and questionnaire survey}

The data collection was started on 18th August 2020 and completed on 31st October 2020 taking a total of 9 weeks. The areas close to the roadways (national highway, main arterial roads, secondary and tertiary roads) were selected for the survey in the main town of Baramulla district, located in north India. The center of the area map was located, and the direction of starting the survey was chosen randomly by rotating a bottle and the direction to which it finally pointed was chosen as the direction of starting the survey. A door-to-door survey was conducted by the authors and participants were selected by consecutive sampling. The participants meeting the eligibility criteria and giving informed consent were taken into the study. A sample of 909 adults comprised the final study population. Only adults with age greater than 18 years were taken into the study as the development of CAD below the age of 18 years is rare (Rubin and Borden 2012). The characteristic of the study sample as compared to that of the target population is given in Table 1. A structured questionnaire (Online resource 1) comprising of 3 sections was used to obtain the required information. After socializing with the members of the family, the whole procedure and purpose of the survey were explained in the local Kashmiri language. At least one participant per household was interviewed during the process. Participation in the survey was completely voluntary and verbal consent was taken from the participants. No incentives were paid to the participants of the study. The first section enquired about the sociodemographic, living conditions, and lifestyle-related questions, the second section consisted of questions about noise sensitivity, and the third section evaluated the self-reported stress levels and sleep quality.

\section{Selection of covariates}

One of the main issues concerning the estimation of unbiased direct effects of an exposure variable on the outcome variable is the selection of the appropriate number of covariates. For the present study, the direct effects of traffic noise on CAD were obtained by controlling for all the necessary mediators and confounders through the usage of DAG (directed acyclic graph) (Shrier and Platt 2008; Austin et al. 2019; Wouk et al. 2019). The development of DAG was done using the webbased software DAGitty (Textor et al. 2011). The covariates

Table 1 A comparison of the characteristics of the study sample and

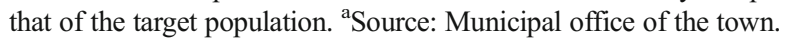

\begin{tabular}{lll}
\hline Characteristic & Study sample & Target population $^{\text {a }}$ \\
\hline Gender & & \\
Male & 41.36 & 43.75 \\
Female & 58.64 & 56.25 \\
\%of individuals with age & & \\
18-40 years & 29.72 & 31.26 \\
40-70 years & 53.12 & 50.62 \\
$>70$ years & 17.16 & 18.12 \\
Married & 60.32 & 65.36 \\
Educational level & & \\
Below graduation & 37.85 & 35.23 \\
Graduation or above & 62.12 & 64.77 \\
\hline
\end{tabular}


used were based on the extensive literature review, documenting the covariates' associations with outcome and exposure. Some of the covariates like "residence period," "bedroom window orientation," and "sensitivity" that were not obtained in the literature review but are considered to be important for the associations between traffic noise and CAD were also added to the developed model. The DAG models were developed based on the perceived causal link between traffic noise and CAD. The model is shown in Fig. 1. The covariates required for the model were obtained through the questionnaire survey. The DAGitty software evaluates the minimum variable set that needs to be adjusted for estimating the unbiased direct effects of traffic noise on CAD. In the present study, the minimum variable set estimated included "age," "bedroom window orientation," "body mass index," "chronic diseases," "physical activity," "sensitivity," "sleep quality," and "stress level." The residence period was also considered to be an important factor hence was also included in the model development.

\section{Study instruments}

Sensitivity to noise was measured by using a single item from Weinstein's Noise Sensitivity Scale "I am sensitive to noise." The six response categories were transformed into three as follows: "low sensitivity" (disagrees strongly, disagree fairly),

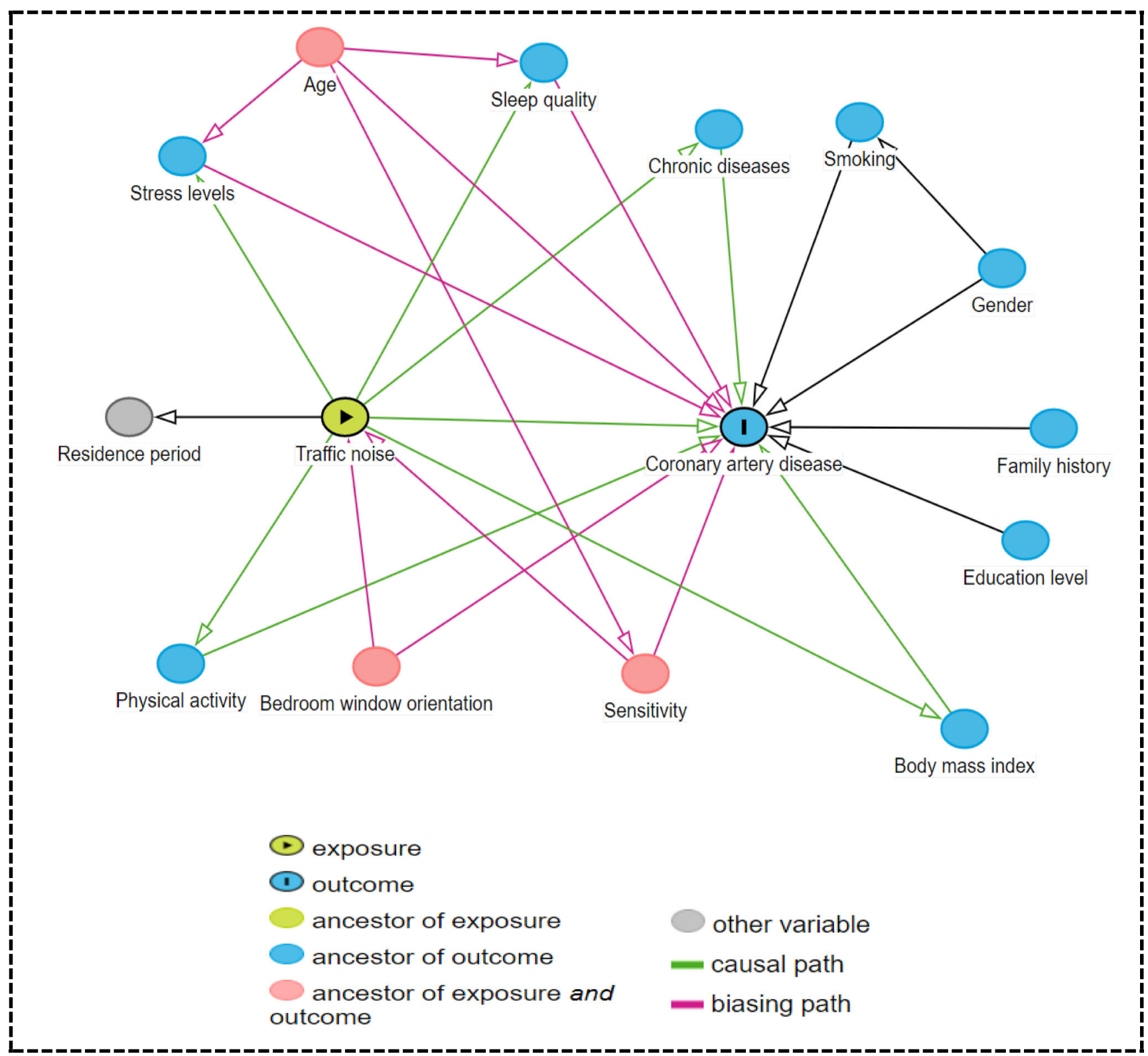

Fig. 1 Directed acyclic graph for selecting the minimum required adjustment set of confounders or mediators based on the perceived causal association 
"medium sensitivity" (disagrees slightly, agree slightly), and "high sensitivity" (agree fairly, agree strongly). The same procedure has been followed in another study as well (Sygna et al. 2014). For assessing the stress levels, modified PSS-10 (Perceived Stress Scale) scale originally developed by Cohen et al. (Cohen et al. 1983) was used. The scale consists of responding to 10 different situations on a Likert scale of 0 to 4 with 0 meaning "never" and 4 meaning "very often." The scale consists of 4 reverse-coded questions for which the response code was subtracted from 4 to get the final score. The respondents were classified as having "low stress" (if the total PSS score was 0 to13), "moderate stress" (if the total PSS score was 14 to 26), and "high stress" (if the total PSS score was 27 to 40). The scale is a valid and reliable tool for the Indian context as well (Pangtey et al. 2020). To measure the sleep quality of the respondents, PSQI (Pittsburgh Sleep Quality Index) scale (Smyth 2002) was used. The scale consists of evaluating seven clinically relevant domains of sleep during the past month in adults which include "subjective sleep quality," "sleep latency," "sleep duration," "sleep efficiency," "sleep disturbances," "use of sleep medication," and "daytime dysfunction." The respondents rated themselves on a Likert scale of 0 to 3, where 3 reflected the "negative extreme" on the Likert scale. The global score of the seven components was divided into three levels with 0 to 1 meaning "excellent sleep quality," 3 to 5 meaning "good sleep quality," and 6 to 21 meaning "poor sleep quality." The scale is a valid tool for assessing sleep quality for the Indian population as well (Manzar et al. 2015). BMI (body mass index)-related data was also reported by respondents in the questionnaire itself. For stress levels, "low stress level" was chosen as the reference level, while for sleep quality, "good" level was chosen as the reference level, while as for sensitivity, "low" level was chosen as the reference level.

\section{Assessment of coronary artery disease}

The cases were identified in two ways. One was the selfreporting about the disease diagnosed by a doctor or qualified medical practitioner, and the second one was a positive response to the following two questions "During the last 5 years have you been diagnosed with any of these diseases COPD, Diabetes, Kidney Disease, High Total Cholesterol/Heart Disease/High Blood Pressure?" and "During the past 5 years have you been diagnosed with any of the heart-related issues like myocardial infarction/angina pectoris?" A similar procedure has also been reported from another study carried out in West Bengal, India (Banerjee et al. 2014). To reconfirm the positive cases, a photocopy of the latest available prescription was requested from the respondents. All the collected photocopies were cross-verified by a qualified medical practitioner independently.
The risk factors associated with CAD that have been established in the literature, viz., family history, smoking, physical activity, stress, presence of other comorbidities, education level, BMI, sensitivity to noise, bedroom window orientation, and self-reported sleep quality, were considered for possible confounding.

\section{Confounders/mediators for the association of road traffic noise and cardiovascular diseases}

\section{Gender}

It is one of the most important factors considered in studies dealing with CVD. Although the incidence of CVD in women is less as compared to men, many clinical shreds of evidence have demonstrated that the mortality rate is high for women due to poor prognosis following a severe cardiovascular event (Di Giosia et al. 2017). Studies have shown that major forms of CVD like CAD, heart failure, stroke, and aortic diseases have seen higher or nearly similar percentages of women as compared to men (Lerner and Kannel 1986; Hochman et al. 1999; Appelros et al. 2009; Writing Group Members et al. 2016). Possible reasons for the gender differences usually are divided into two categories: one set of factors is known as "common factors," and the other set is known as a "womenspecific set of factors." The common factors including age, hypertension, total cholesterol, and low-density lipoprotein cholesterol have more pronounced effects for men, while smoking, diabetes, high-density lipoprotein, and triglycerides have a more pronounced effect in women (Gao et al. 2019). The women-specific factors include gestational diabetes mellitus, pregnancy-induced hypertension, menopause, preeclampsia, and polycystic ovary syndrome (Sattar and Greer 2002; Appelman et al. 2015).

\section{Age}

Age plays an important role in the increase of disease burden due to CVD. A higher prevalence rate for CVD has been found with the increase in age for both males and females. The functional and electrical defects occurring in aged adults are considered to be the most important reasons for the higher prevalence of CVDs. Besides the development of other risk factors like diabetes and obesity have been found to contribute significantly towards a higher prevalence of CVDs. According to American Heart Association for the years 2013-2017, the percentages of males and females in the age group of 65-74 years diagnosed with hypertension was $70.8 \%$ and $77.7 \%$, respectively. However, the percentages of diagnosed hypertension showed a sharp increase to $80.0 \%$ and $85.6 \%$ for males and females, respectively, in the age group above 75 years (Benjamin et al. 2019). 


\section{Sleep disorders}

There is increasing evidence which reveals that both sleep duration and sleep quality have a significant effect on the prevalence of CVD. The risks for CAD due to poor sleep quality and duration are high in individuals aged 40 years or above. There are several hypothesized mechanisms for the role of sleep disorders in cardiovascular disease prevalence. One of the possible explanations is the lowering of leptin hormone levels and elevation of ghrelin hormone levels leading to the development of obesity and reduction of energy expenditure, two of the most common risk factors for CVDs (Taheri et al. 2004; Chandola et al. 2010; Lao et al. 2018). Another possible explanation is the increased cortisol secretion and alteration of growth hormone metabolism due to sleep fragmentation caused by environmental noise in general and nocturnal noise in particular.

\section{Educational level}

Educational level has been found to influence the risk of developing cardiovascular diseases. Studies have found that lower levels of education are generally associated with higher risks of dying due to any of the CVDs as compared to those with higher levels of education (Kelli et al. 2019). The mechanisms underlying the link between educational level and cardiovascular outcomes are likely multifaceted, involving a complex interplay of poor health literacy exacerbating unhealthy lifestyle habits and drug non-adherence. Without the required education to encourage change, unhealthy habits are more likely to persist, increasing the risk of CVD among those who are less educated compared to those who are more educated. The lower education level to some extent can also serve as an indicator of financial constraints which results in poorer access to health centers, and thus, such a population can present itself with advanced stages of cardiovascular outcomes thereby increasing their risk of mortality and morbidity.

\section{Physical activity}

Regular physical activity reduces the risk of suffering from cardiovascular events at an early age. The role of physical activity in lowering the risk for CVD is also mediated by lowering the risks for some of the well-known risk factors like diabetes, hypertension, and obesity. Epidemiological studies have found that physical activity is effective in the reduction of cardiovascular events by $20 \%$ and an increase in life expectancy by 5 years (Winzer et al. 2018).

\section{Bedroom window orientation}

The role of bedroom window orientation in the development of cardiovascular diseases is mediated by the changes in the exposure levels. Studies have found that exposure to higher levels of traffic noise due to bedroom window orientation result in higher risks for the development of hypertension and other CVDs (Leon Bluhm et al. 2006). Bedrooms with windows facing the streets or roads can prove harmful as this leads to exposure to traffic noise especially during nighttime, thereby leading to the fragmentation of sleep structure without the actual perception of the stressor.

\section{Stress}

Concerning CVD psychological stress takes special prominence because of the obvious links between the brain and heart. Stress forms an integral part of life and can come into play when the individual feels not in control of the surrounding environment. The response of the body to stress occurs via the "fight or flight" mechanism to maintain homeostasis. But prolonged levels of stress can lead to the secretion of stress hormones like cortisol, adrenaline which in the long run increase blood cholesterol, blood sugar levels, and even blood pressure, which are the common risk factors for CVD.

\section{Smoking}

Smoking is one of the major causes of CVD and approximately contributes to every fourth death occurring due to cardiovascular events. The mechanism behind the association of smoking with CVD involves the inflammation of the cells that line the interiors of the blood vessels. It also results in the build-up of plaque inside the arteries, resulting in narrowing down of the lumen of arteries and disturbing the hemodynamic processes occurring inside the body.

\section{Noise sensitivity}

The link between noise sensitivity and CVD occurs indirectly. The levels of psychological disturbance and noise recognition are influenced by various factors of which individual factors like noise sensitivity form an important part. Not all the individuals who are exposed to different levels of environmental stressors like traffic noise are influenced similarly; thus, variations have been found in terms of the prevalence of diseases and other health issues among populations exposed to similar noise levels. Studies conducted have found that environmental noise levels exert their influence on the health status of the exposed individuals via noise sensitivity (Stansfeld and Shipley 2015). Therefore, epidemiological studies assign more importance to noise sensitivity while evaluating the relationship between traffic noise exposure and CVD. 
Body mass index (BMI)

Body mass index is an indicator of obesity which forms an independent risk factor for the development of CVD. The relation between BMI and CVD can be explained due to obesity itself and also on the other hand due to the association of BMI with several medical conditions like hypertension, diabetes, insulin resistance, and reduced sleep quality. Obesity can also lead to the activation of the inflammation process and thereby resulting in atherosclerosis, a well-known risk factor for CVD. Higher BMI levels also lead to hemodynamic changes and also an increase in the aldosterone level which can lead to endothelial dysfunction and ultimately result in CAD (Ebong et al. 2014).

\section{Usage of trap questions}

One of the main issues that remain while getting feedback from the respondents during a questionnaire survey is to ensure that respondents are paying full attention to each question and replying to the best of their abilities. Although it is not possible to ensure that respondents pay $100 \%$ attention while replying, efforts should be put in so that the attention of respondents can be ensured to the maximum. In this direction, we used the concept of "trap questions." We framed three simple questions and randomly placed them at various positions in the questionnaire sheet. The three questions included were:

- Mumbai is the capital of India (Yes/No).

- COVID-19 pandemic started in July 2020 (Yes/No).

- COVID-19 emerged from the USA (Yes/No).

Any response sheet having two incorrect replies was discarded for further analysis. The selected questions were such that even individuals with less knowledge could easily respond to them. After the survey was finished, we found 6 response sheets that failed to meet the criterion. Knowing that discarding the response sheet based on merely reporting incorrectly to few questions may induce some degree of bias, a further evaluation of these 6 response sheets was done. It was revealed that all three trap questions were answered incorrectly. Besides a patterned set of responses to other questions along with a good amount of self-reporting questions were left unanswered. This further strengthened our decision of excluding these 6 response sheets. The usage of the attention questions can help in ensuring the attention of the respondents, especially when the respondents are not provided any incentives for taking part in the survey. The lack of incentives can make the respondents less interested, and hence, they can provide inappropriate or inaccurate information. The implementation of such questions can be helpful in future research as well.

\section{Assessment of the noise levels}

The noise levels to which the respondents are exposed were obtained by using TNM 2.5 (Traffic Noise Model) model developed by FHWA (Federal highway administration) which is suitable for Indian road traffic conditions (Shukla et al. 2009). The noise level index was chosen as the average $L_{d e n}$ which takes into account the noise levels for daytime, evening time, and also nighttime with penalties of $5 \mathrm{~dB}(\mathrm{~A})$ for the evening and $10 \mathrm{~dB}(\mathrm{~A})$ for nighttime. Studies concerning traffic noise and CVD differ in terms of the noise index used. While studies using the average noise levels like $L_{d e n}, L_{d n}$, $\mathrm{L}_{\text {eq, day }}$, and $\mathrm{L}_{\text {eq,night }}$ consider that total noise exposure should be considered while evaluating the effect of traffic noise on cardiovascular outcomes (Selander et al. 2009; Begou and Kassomenos 2020), other studies have based their associations using event-based indexes like IR (intermittency ratio) (Basner et al. 2011; Héritier et al. 2017; Brink et al. 2019). The usage of IR is based on the evidence which revealed that temporal characteristics of noise also play an important role in nocturnal awakening events. Evidence has shown that event-related awakenings, cardiovascular arousals, and body movements depend on maximum noise level, and as such, the average noise levels cannot predict the cardiovascular outcomes well (Héritier et al. 2017). Despite the heterogeneity, both the type indexes are being used in epidemiological studies dealing with cardiovascular outcomes. Noise maps and the facade maps of the area were prepared using Soundplan V8.2 software from Braunstein \& Berndt $\mathrm{GmbH}$, Backnang, Germany. The input for the maps includes GPS coordinates of the survey area, classified road traffic volume, traffic speed, pavement surface type, the height of the residential buildings, and lane width. The data concerning road traffic volume and traffic speed were obtained through videographic measurements. Pavement surface type, the height of the residential buildings, and lane width were obtained through field visits. For the grid noise map, the grid space of $15 \mathrm{~m}$ and calculated $2 \mathrm{~m}$ above the ground was selected. For the facade map, one receiver was placed at the center of the facade and the maximum value for a particular building was selected as the exposure level. The noise map and facade map of the study area are shown in Figs. 2 and 3, respectively.

\section{Usage of noise maps and facade maps}

Noise maps are generally used for representing the overall acoustic environment of the area. In the present study, the noise map developed was used for representing the overall acoustic environment of the study area. It was also used to divide the residential areas into quiet and noisy areas. However, the exposure level and the number of individuals exposed to different noise levels were estimated using facade 


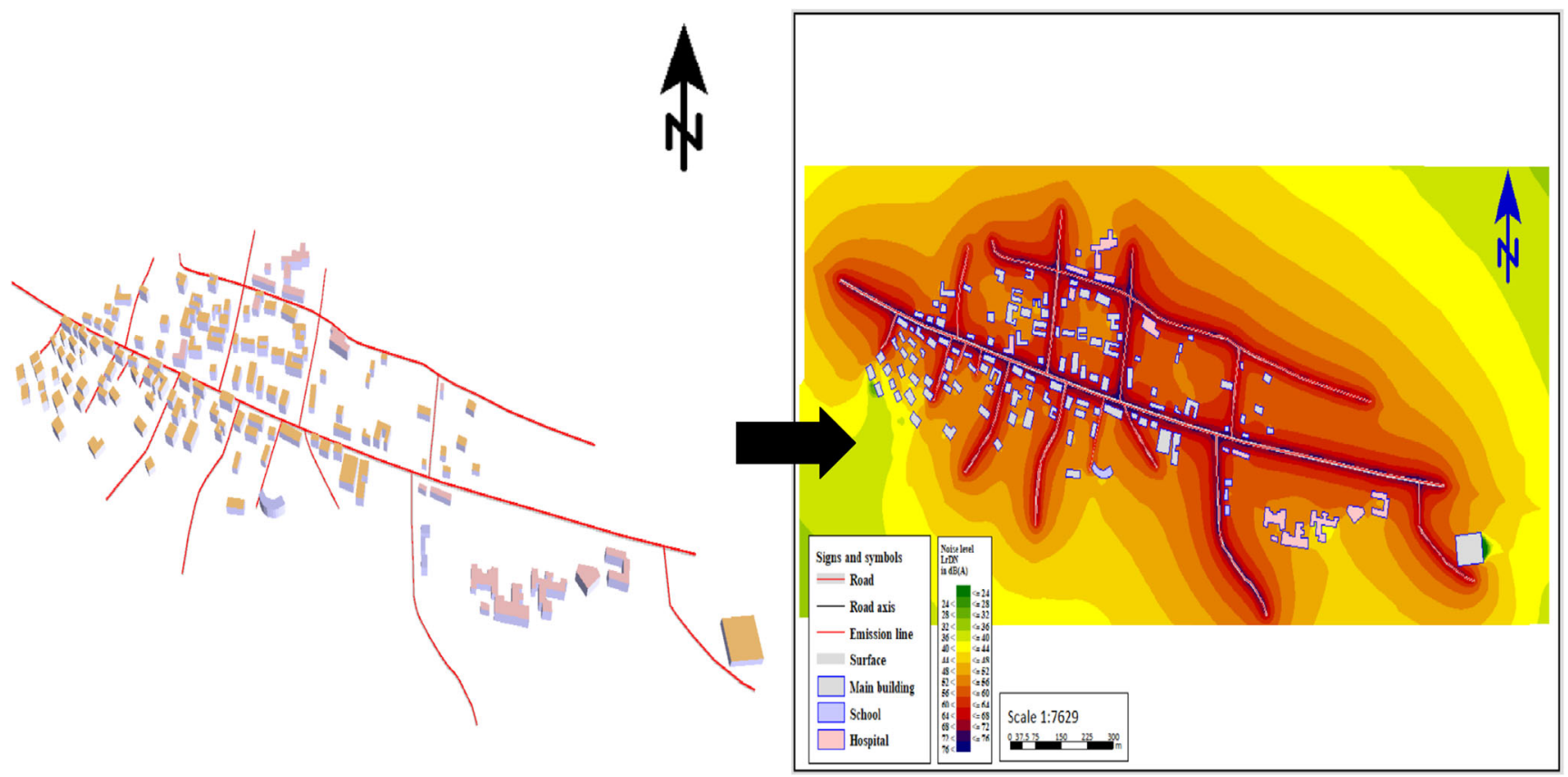

Fig. 2 A 3D view of the study area and the noise map developed for the area

maps. Areas with $\mathrm{L}_{\mathrm{den}}<60 \mathrm{~dB}(\mathrm{~A})$ were classified as "quiet areas" and those with $\mathrm{L}_{\mathrm{den}} \geq 60 \mathrm{~dB}(\mathrm{~A})$ were classified as "noisy areas." Those respondents residing in the quiet areas were selected as the reference group, and those residing in the noisy areas were selected as the exposed group. The selection of $60 \mathrm{~dB}(\mathrm{~A})$ as the cut-off value was done because of two reasons - firstly, the median value of the noise levels was $63.85 \mathrm{~dB}(\mathrm{~A})$ for the study, and secondly, the threshold values for $\mathrm{L}_{\text {den }}$ suggested is $50 \mathrm{~dB}(\mathrm{~A})$ (Belojevic and SaricTanaskovic 2002; Babisch 2006) - but due to different road traffic conditions prevalent in India, a slightly higher value of $60 \mathrm{~dB}(\mathrm{~A})$ was chosen.

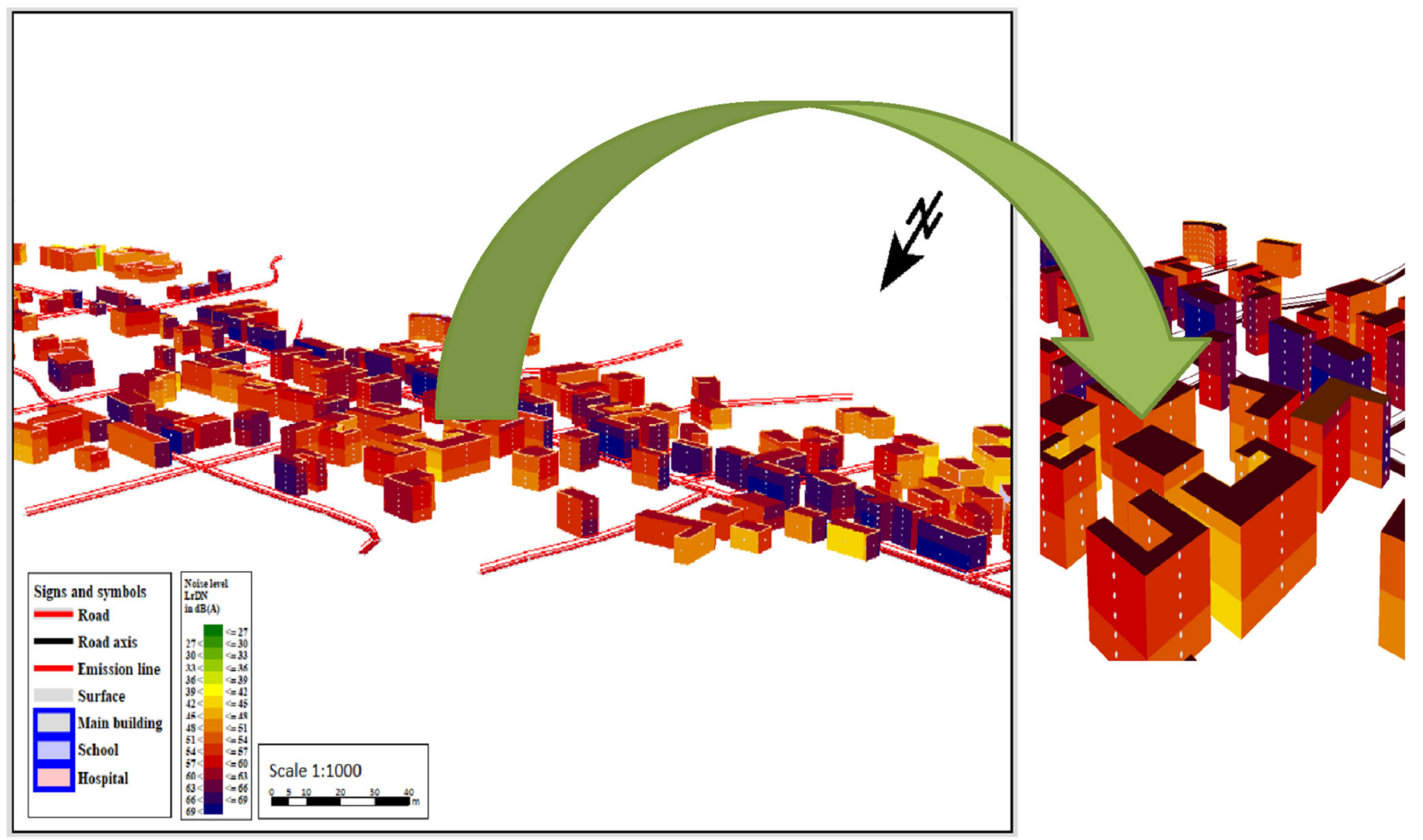

Fig. 3 Facade map of the study area with an enlarged view of the building facades 


\section{Validation of the modeled noise levels}

As the study utilizes the modeled noise levels for obtaining the exposure level of residents, the validation of the modeled noise levels becomes necessary. For this purpose, 32 sites were selected in the entire study area where noise levels were measured using a Casella CEL-633C class 1 sound level meter, which was calibrated using Casella CEL-120/1 class 1 acoustic calibrator. The modeled noise levels were obtained directly from the noise map, while the measured values were obtained from the field measurements. The sound level meter was pre-installed at these sites and 24-h noise measurements were taken. The $\mathrm{L}_{\mathrm{den}}$ (24 h) values were directly obtained from the Casella software. The noise measurements were taken during the same period as that of the questionnaire survey, i.e., 18th August 2020 to 31 st October 2020. A paired sample t-test and Pearson's correlation coefficient were obtained to check the validity of the modeled noise levels both statistically and quantitatively. The results from the correlation analysis revealed that there was a high and significant correlation between the measured and modeled noise levels, $r=.921, p$ (two-tailed) $<0.01$. A scatterplot between the modeled and measured noise levels is shown in Fig. 4. On average, measured noise levels were slightly higher $(\mathrm{M}=67.15, \mathrm{SD}=$ 4.43) than the predicted noise levels $(\mathrm{M}=66.82, \mathrm{SD}=4.91)$ with $(\mathrm{t}(31)=.964, \mathrm{p}=.343)$.

\section{Statistical analysis}

The data were stratified based on the gender variable, and each stratum was subjected to parametric/non-parametric tests for continuous variables and chi-square test for categorical variables stratified by the two exposure groups. Continuous variables like age, noise level, residence period, and BMI were tested for normality using KolmogorovSmirnov and Shapiro-Wilk test. Both the tests revealed a $p$ value $<0.001$, suggesting that the data was not normally

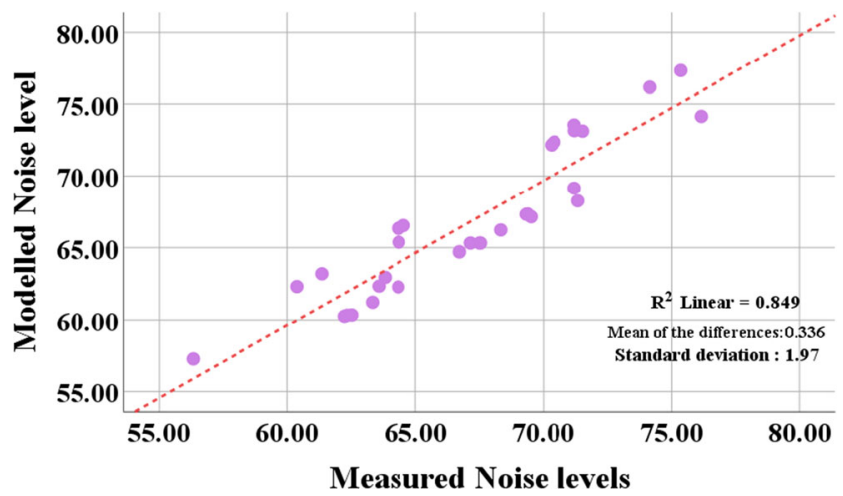

Fig. 4 Scatterplot for the comparison between predicted and measured noise levels distributed. For these variables, we, therefore, performed the non-parametric Wilcoxon rank-sum test. For categorical variables, we performed a chi-square test to compare the differences between the two exposure groups. Univariate logistic regression was done for each of the risk factors of CAD. The association between the $\mathrm{L}_{\mathrm{den}}$ index and the risk of CAD (expressed as odds ratio) was evaluated both using noise level as a continuous variable as well as the categorical variable through logistic regression analysis. The odds ratio was evaluated for unadjusted, partially adjusted, and fully adjusted models. The partial adjustment was done for age, residence period, stress levels, and BMI, while the full adjustment was done for chronic disease, sensitivity, family history, physical activity, bedroom window orientation, and sleep quality, in addition to the variables of partially adjusted model. Results from the analysis were represented in the form of an odds ratio along with $95 \%$ confidence intervals. All the analysis was performed using SPSS V25.0 software.

\section{Results}

A total of 909 adults were selected for the study. Table 2 presents the descriptive statistics of the study participants. The results are based on noisy and quiet areas for both males and females. A total of 376 males and 533 females participated in the survey. Overall, the study sample was a good representation of the target population. Both males and females from the noisy and quiet areas differed in terms of age. In addition to this males from noisy and quiet areas differed significantly in terms of sensitivity. There was a significant age difference for both males and females living in noisy and quiet areas with higher-aged residents residing in noisy areas. The exposure levels to which males and females were subjected differed significantly with females being subjected to slightly higher noise levels as compared to males. Overall, the prevalence of CAD was $8.80 \%$ out of which $3.35 \%$ of the cases were reported from quiet areas and $11.46 \%$ of the cases were reported from noisy areas. The prevalence was more in noisy areas for both males and females but males reported higher prevalence as compared to females. In terms of exposure, $32.78 \%$ of people were exposed to noise levels below $60 \mathrm{~dB}(\mathrm{~A}), 22.66 \%$ were exposed to noise levels between 60 and $65 \mathrm{~dB}(\mathrm{~A}), 24.97 \%$ were exposed to noise levels between 65 and $70 \mathrm{~dB}(\mathrm{~A})$, and $19.58 \%$ were exposed to noise levels $>70 \mathrm{~dB}(\mathrm{~A})$.

The results from the univariate logistic regression for both genders, showing the association between CAD prevalence and independent risk factors, are shown in Table 3. For both genders, age, residence period, BMI, presence of other chronic diseases, bedroom window orientation, sensitivity, and sleep quality were associated with the odds of self-reported CAD. In 
Table 2 Characteristics of the respondents stratified based on gender and noise level around the residence

\begin{tabular}{|c|c|c|c|c|c|c|}
\hline \multirow[t]{2}{*}{ Characteristic } & \multicolumn{3}{|l|}{ Males $(n=376)$} & \multicolumn{3}{|c|}{ Females $(n=533)$} \\
\hline & $\begin{array}{l}\text { Quiet area }{ }^{\mathrm{a}} \\
(\mathrm{n}=99)\end{array}$ & $\begin{array}{l}\text { Noisy area }^{\mathrm{b}} \\
(\mathrm{n}=277)\end{array}$ & $\mathrm{p}$ value & $\begin{array}{l}\text { Quiet area }^{\mathrm{a}} \\
(\mathrm{n}=199)\end{array}$ & $\begin{array}{l}\text { Noisy area }^{\mathrm{b}} \\
(\mathrm{n}=334)\end{array}$ & $\mathrm{p}$ value \\
\hline $\mathrm{L}_{\mathrm{den}}($ mean $\pm \mathrm{SD})$ & $53.87 \pm 3.36$ & $67.84 \pm 4.96$ & $<0.001$ & $54.40 \pm 3.41$ & $68.56 \pm 5.11$ & $<0.001$ \\
\hline Age $($ mean \pm SD $)$ & $38.87 \pm 12.51$ & $49.95 \pm 13.99$ & $<0.001$ & $34.04 \pm 7.48$ & $56.33 \pm 9.03$ & $<0.001$ \\
\hline $\mathrm{BMI}($ mean $\pm \mathrm{SD})$ & $25.45 \pm 2.32$ & $25.72 \pm 2.38$ & 0.360 & $25.62 \pm 2.45$ & $25.56 \pm 2.33$ & 0.774 \\
\hline Residence period ( mean \pm SD ) & $9.58 \pm 3.60$ & $9.88 \pm 3.81$ & 0.560 & $9.94 \pm 3.75$ & $10.00 \pm 3.84$ & 0.895 \\
\hline Chronic disease (n) & & & 0.729 & & & 0.269 \\
\hline No & 68 & 185 & & 150 & 237 & \\
\hline Yes & 31 & 92 & & 49 & 97 & \\
\hline Sensitivity (n) & & & 0.001 & & & 0.581 \\
\hline Low & 33 & 75 & & 48 & 74 & \\
\hline Medium & 23 & 124 & & 72 & 136 & \\
\hline High & 43 & 78 & & 79 & 124 & \\
\hline Stress (n) & & & 0.350 & & & 0.926 \\
\hline Low & 55 & 153 & & 99 & 169 & \\
\hline Moderate & 32 & 75 & & 53 & 91 & \\
\hline High & 12 & 49 & & 47 & 74 & \\
\hline Bedroom window towards road $(\mathrm{n})$ & & & 0.339 & & & 0.159 \\
\hline No & 59 & 180 & & 115 & 172 & \\
\hline Yes & 40 & 97 & & 84 & 162 & \\
\hline Family history (n) & & & 0.939 & & & 0.195 \\
\hline No & 88 & 247 & & 170 & 298 & \\
\hline Yes & 11 & 30 & & 29 & 36 & \\
\hline Smoking (n) & & & 0.524 & & & \\
\hline No & 51 & 153 & & & & \\
\hline Yes & 48 & 124 & & & & \\
\hline Physical activity (n) & & & 0.474 & & & 0.712 \\
\hline Sedentary & 29 & 92 & & 101 & 164 & \\
\hline Active & 70 & 185 & & 98 & 170 & \\
\hline Education level (n) & & & 0.838 & & & 0.901 \\
\hline Below high school & 8 & 28 & & 24 & 36 & \\
\hline Up to higher secondary & 26 & 70 & & 56 & 96 & \\
\hline Above higher secondary & 65 & 179 & & 119 & 202 & \\
\hline Sleep quality & & & 0.537 & & & 0.174 \\
\hline Poor & 34 & 105 & & 61 & 94 & \\
\hline Good & 22 & 75 & & 34 & 41 & \\
\hline Excellent & 43 & 97 & & 104 & 199 & \\
\hline Prevalence of disease & & & 0.011 & & & 0.005 \\
\hline Yes & 5 & 41 & & 5 & 29 & \\
\hline No & 94 & 236 & & 194 & 305 & \\
\hline
\end{tabular}

$\mathrm{SD}=$ standard deviation

${ }^{\mathrm{a}} \mathrm{L}_{\mathrm{den}} \leq 60 \mathrm{dBA}$

${ }^{\mathrm{b}} \mathrm{L}_{\mathrm{den}}>60 \mathrm{dBA}$

addition to these factors, family history of CAD and physical activity were significantly associated with the odds of selfreported CAD for males. Smoking was only considered for males as women in this part of the globe do not smoke. For sleep quality and sensitivity, the odds for CAD were reported by selecting appropriate levels as the reference levels. 
Table 3 Risk factors associated with coronary artery disease in adult population stratified by gender

\begin{tabular}{|c|c|c|c|c|c|c|}
\hline \multirow[t]{2}{*}{ Independent variable } & \multicolumn{3}{|c|}{ Male $(\mathrm{n}=376)$} & \multicolumn{3}{|c|}{ Female $(n=533)$} \\
\hline & $\mathrm{UOR}^{\mathrm{a}}$ & $95 \% \mathrm{CI}$ & $\mathrm{p}$ value & $\mathrm{UOR}^{\mathrm{a}}$ & $95 \% \mathrm{CI}$ & $\mathrm{p}$ value \\
\hline Age (years) & 1.02 & $1.01-1.05$ & 0.033 & 1.03 & $1.01-1.06$ & 0.019 \\
\hline $\mathrm{RP}^{\mathrm{b}}$ (years) & 1.14 & $1.05-1.24$ & 0.003 & 1.13 & $1.02-1.25$ & 0.017 \\
\hline $\mathrm{BMI}^{\mathrm{c}}\left(\mathrm{kg} / \mathrm{m}^{2}\right)$ & 1.17 & $1.02-1.35$ & 0.021 & 1.31 & $1.09-1.55$ & 0.003 \\
\hline Physical activity ${ }^{\mathrm{d}}$ & 1.93 & $1.03-3.61$ & 0.039 & 1.43 & $0.69-2.98$ & 0.340 \\
\hline Chronic disease $^{\mathrm{e}}$ & 2.55 & $1.36-4.75$ & 0.003 & 3.05 & $1.47-6.35$ & 0.003 \\
\hline Smoking ${ }^{\mathrm{f}}$ & 1.48 & $0.79-2.75$ & 0.213 & & & \\
\hline $\mathrm{BWO}^{\mathrm{g}}$ & 3.51 & $1.85-6.65$ & $<0.001$ & 3.03 & $1.37-6.72$ & 0.006 \\
\hline Family history $^{\text {h }}$ & 3.14 & $1.45-6.82$ & 0.004 & 2.23 & $0.92-5.41$ & 0.075 \\
\hline \multicolumn{7}{|l|}{ Sensitivity ${ }^{\mathrm{i}}$} \\
\hline Low & Ref & & & & & \\
\hline Medium & 5.07 & $1.71-15.09$ & 0.004 & 8.07 & $1.04-62.45$ & 0.046 \\
\hline High & 4.54 & $1.49-13.89$ & 0.008 & 11.06 & $1.45-84.18$ & 0.020 \\
\hline \multicolumn{7}{|l|}{ Sleep quality ${ }^{\mathrm{j}}$} \\
\hline Poor & 2.94 & $1.38-6.24$ & 0.005 & 4.02 & $1.75-9.26$ & 0.001 \\
\hline Excellent & 1.43 & $0.58-3.51$ & 0.433 & 2.33 & $0.76-7.18$ & 0.140 \\
\hline Good & Ref & & & & & \\
\hline
\end{tabular}

${ }^{\text {a }} U O R$ unadjusted odds ratio

${ }^{\mathrm{b}} R P$ residence period (in years)

${ }^{\mathrm{c}} B M I$ body mass index (in $\mathrm{kg} / \mathrm{m}^{2}$ )

dPhysical activity has "active" as the reference level

"Chronic disease has "no chronic disease" which was chosen as the reference level

${ }^{\mathrm{f}}$ Was not reported for women

${ }^{\mathrm{g}} B W O$ bedroom window orientation with "no means not towards the street" as the reference level

${ }^{\text {h}}$ Family history has "no family history" as the reference level

iSensitivity has "low noise sensitivity" as the reference level

${ }^{\mathrm{j}}$ Sleep quality has "excellent quality" as the reference level

Hierarchical logistic regression with relevant parameters was performed for both males and females to evaluate the odds for CAD given the exposure to a certain noise level. For the unadjusted model, respondents living in the noisy areas were having a higher risk $(\mathrm{OR}=2.05 ; 95 \% \mathrm{CI}=1.09$ to 3.84) as compared to those living in the quiet streets. When the model was partially adjusted for age, stress levels, BMI, and residence period, the risk increased slightly but significantly $(\mathrm{OR}=2.18 ; 95 \% \mathrm{CI}=1.29$ to 3.70$)$. After fully adjusting the model, the risks associated with living in noise areas increased to $2.25(\mathrm{OR}=2.25 ; 95 \% \mathrm{CI}=1.38$ to 3.67). For female respondents, the unadjusted model resulted in the lower but significant risk for those living in noisy streets $(\mathrm{OR}=1.87 ; 95 \% \mathrm{CI}=1.22$ to 2.89$)$. Partial adjustment of the model for females led to a small increment in the risk ( $\mathrm{OR}=1.97 ; 95 \% \mathrm{CI}=1.35$ to 2.86$)$. After the model was fully adjusted, the risks associated with females living in noisy streets increased to 2.07 as compared to those living in quiet areas $(\mathrm{OR}=1.37$ to 3.13$)$. For male respondents the unadjusted model resulted in lower risk for those living in noisy areas $(\mathrm{OR}=2.36 ; 95 \% \mathrm{CI}=1.14$ to 4.88 ) as compared to when the model was partially adjusted for age, stress levels, BMI, and residence period $(\mathrm{OR}=$ $2.44 ; 95 \% \mathrm{CI}=1.38$ to 4.30 ). After fully adjusting the model, there was an increase in the risk for those living in noisy areas $(\mathrm{OR}=2.61 ; 95 \% \mathrm{CI}=1.84$ to 3.72$)$. The results are shown in Table 4.

To evaluate the threshold value for the traffic noise at which the risk for CAD due to traffic noise becomes significant, the noise level data was categorized using an interval size of $5 \mathrm{~dB}(\mathrm{~A})$. The levels were categorized from noise level below $50 \mathrm{~dB}(\mathrm{~A})$ (which was taken as a reference group) to be more confident about the threshold value (Fig. 5). It can be seen that a significant increasing trend in the risk for $\mathrm{CAD}$ is beyond $60 \mathrm{~dB}(\mathrm{~A})$. Below $60 \mathrm{~dB}(\mathrm{~A})$, the risks for $\mathrm{CAD}$ are not significant. For the range of $61-65 \mathrm{~dB}(\mathrm{~A})$, the adjusted odds ratio was $2.01(95 \% \mathrm{CI}=1.05$ to 2.97$)$. Beyond this interval, there was a significant increase of $4 \%$ and $9.45 \%$ in the risk for the two remaining groups of $66-70 \mathrm{~dB}(\mathrm{~A})$ and $>70$ $\mathrm{dB}(\mathrm{A})$, respectively. Evaluation of the risk due to traffic 
Table 4 Hierarchical logistic regression models for CAD prevalence for the complete sample and stratified for males and females. Odds ratio are calculated per $5 \mathrm{~dB}(\mathrm{~A})$ increment in the noise levels

\begin{tabular}{|c|c|c|c|c|c|}
\hline $\begin{array}{l}\text { Traffic noise level }\left(\mathrm{L}_{\mathrm{den}}\right) \\
\text { Continuous per } 5 \mathrm{~dB}(\mathrm{~A}) \\
\text { increment }\end{array}$ & Type of area & $\begin{array}{l}\mathrm{CAD}^{*} \\
\text { prevalence } \\
(\%)\end{array}$ & $\begin{array}{l}\text { Unadjusted model } \\
\text { Odds ratio }(95 \% \mathrm{CI}) \text {, } \\
\text { p value }\end{array}$ & $\begin{array}{l}\text { Partially adjusted } \\
\text { model }^{\mathrm{a}} \\
\text { Odds ratio }(95 \% \mathrm{CI}), \\
\text { p value }\end{array}$ & $\begin{array}{l}\text { Fully adjusted model }{ }^{\mathrm{b}} \\
\text { Odds ratio }(95 \% \mathrm{CI}), \\
\text { p value }\end{array}$ \\
\hline \multirow[t]{2}{*}{ For full sample ${ }^{\mathrm{c}}$} & Quiet area $\left(\mathrm{L}_{\mathrm{den}} \leq 60 \mathrm{~dB}(\mathrm{~A})\right)$ & 3.35 & 1 & 1 & 1 \\
\hline & Noisy area $\left(\mathrm{L}_{\mathrm{den}}>60 \mathrm{~dB}(\mathrm{~A})\right)$ & 11.46 & $\begin{array}{c}2.05(1.09-3.84) \\
p=0.001\end{array}$ & $\begin{array}{c}2.18(1.29-3.70) \\
p=0.021\end{array}$ & $\begin{array}{c}2.25(1.38-3.67) \\
p<0.001\end{array}$ \\
\hline \multirow[t]{2}{*}{ Males } & Quiet area $\left(\mathrm{L}_{\mathrm{den}} \leq 60 \mathrm{~dB}(\mathrm{~A})\right)$ & 5.10 & 1 & 1 & 1 \\
\hline & Noisy area $\left(\mathrm{L}_{\mathrm{den}}>60 \mathrm{~dB}(\mathrm{~A})\right)$ & 14.80 & $\begin{array}{c}2.36(1.14-4.88) \\
p=0.013\end{array}$ & $\begin{array}{c}2.44(1.38-4.30) \\
p=0.034\end{array}$ & $\begin{array}{c}2.61(1.84-3.72) \\
p=0.014\end{array}$ \\
\hline \multirow[t]{2}{*}{ Females } & Quiet area $\left(\mathrm{L}_{\mathrm{den}} \leq 60 \mathrm{~dB}(\mathrm{~A})\right)$ & 2.51 & 1 & 1 & 1 \\
\hline & Noisy area $\left(\mathrm{L}_{\mathrm{den}}>60 \mathrm{~dB}(\mathrm{~A})\right)$ & 8.68 & $\begin{array}{c}1.87(1.22-2.89) \\
p=0.017\end{array}$ & $\begin{array}{c}1.97(1.35-2.86) \\
\mathrm{p}=0.033\end{array}$ & $\begin{array}{c}2.07(1.37-3.13) \\
p=0.029\end{array}$ \\
\hline
\end{tabular}

${ }^{*}$ CAD coronary artery disease

${ }^{a}$ Model adjustments made for age, body mass index, stress levels, residence period

${ }^{\mathrm{b}}$ Model adjustments made for age, body mass index, stress levels, residence period, chronic disease, sensitivity, physical activity, bedroom window orientation, sleep quality

noise based on age group revealed an increasing trend in the risk for suffering from CAD. The vulnerable population age group with statistically significant risk was found to be starting from 50 to 59 years with an odds ratio of 2.15 ( $95 \% \mathrm{CI}=1.08$ to 3.21 ). Beyond this age group, the odds ratio were $2.23(95 \% \mathrm{CI}=1.11$ to 3.35$)$ and $2.31(95 \% \mathrm{CI}=$ 1.08 to 3.54) for the age groups of 60 to 69 years and $>70$ years, respectively. This is shown in Fig. 6. The risk of suffering from CAD due to traffic noise across the three different levels of noise sensitivity revealed that respondents with medium sensitivity had a higher risk for suffering from CAD with an odds ratio of 2.25 (95\% CI $=1.19$ to 3.32 ) as compared to the reference group (low sensitivity).

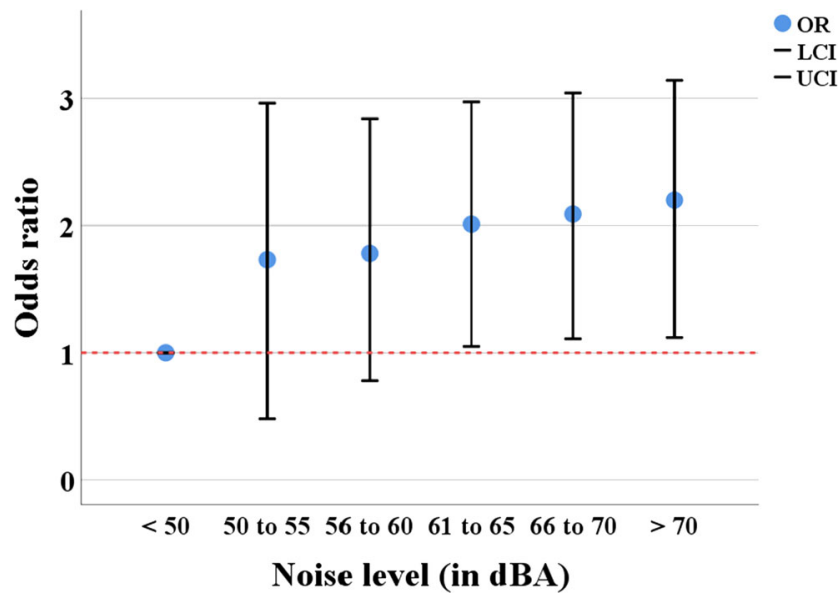

Fig. 5 Odds ratio for the risk of coronary artery disease based on noise level. The model was adjusted for age, body mass index, stress levels, residence period, chronic disease, sensitivity, physical activity, bedroom window orientation, and sleep quality. OR, odds ratio; LCI, lower confidence interval; UCI, upper confidence interval
The risk was slightly higher among the respondents with high sensitivity to noise and had an odds ratio of 2.39 (95\% $\mathrm{CI}=1.22$ to 3.56 ) as compared to the reference group. This is shown in Fig. 7.

The risk of suffering from $\mathrm{CAD}$ due to traffic noise among respondents across different stress levels revealed that respondents reporting "moderate" and "high" levels of stress were having significantly higher risk as compared to the reference group (low stress level). The risk for the occurrence of CAD was $2.01(95 \% \mathrm{CI}=1.05$ to 2.97$)$ and $2.17(95 \% \mathrm{CI}=1.27$ to 3.08) for moderately and highly stressed respondents, respectively. This is shown in Fig. 8. Based on the sleep quality reported by the respondents, "poor sleep" quality was

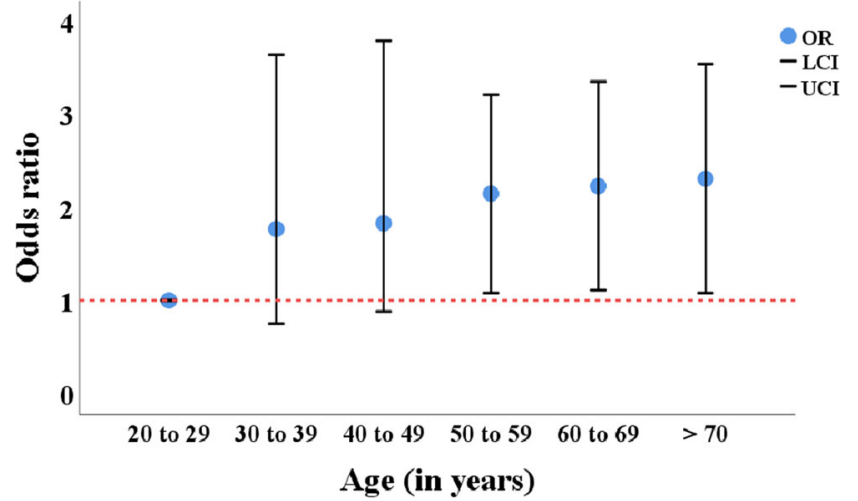

Fig. 6 Odds ratio for the risk of coronary artery disease due to traffic noise based on age groups. The model was adjusted for sleep quality, body mass index, stress levels, residence period, chronic disease, sensitivity, physical activity, and bedroom window orientation. OR, odds ratio; LCI, lower confidence interval; UCI, upper confidence interval 


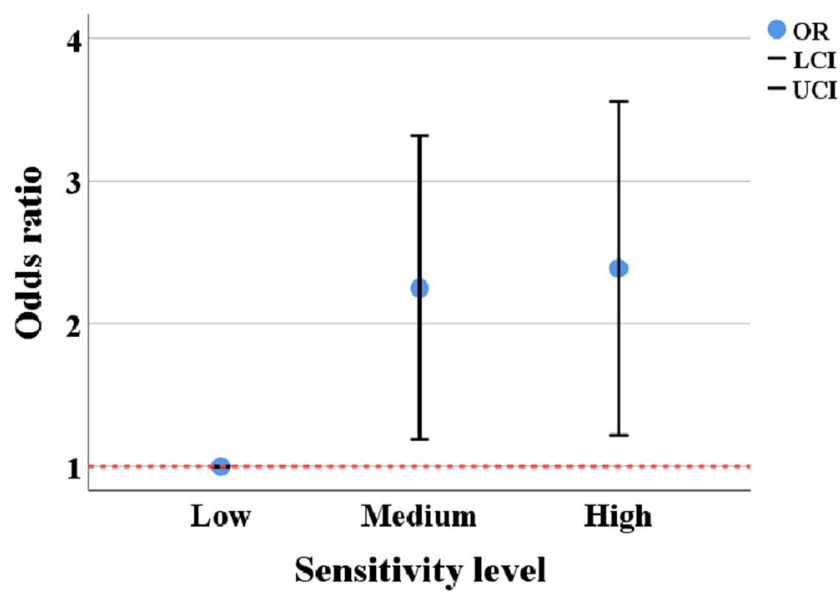

Fig. 7 Odds ratio for the risk of coronary artery disease due to traffic noise based on sensitivity level. The model was adjusted for age, body mass index, stress levels, residence period, chronic disease, sleep quality, physical activity, and bedroom window orientation. OR, odds ratio; LCI, lower confidence interval; UCI, upper confidence interval

associated with a higher risk for CAD due to traffic noise as compared to the reference group (good sleep) quality. The risk for the occurrence was 2.09 times higher $(95 \% \mathrm{CI}=1.08$ to 3.11). However, there was no statistically significant difference in the risk for CAD due to traffic noise for "good" and "excellent sleep" quality. This is clearly shown in Fig. 9. All the effect modifications based on age group, stress levels, sensitivity, and sleep quality along with their significance values are shown in Table 5.

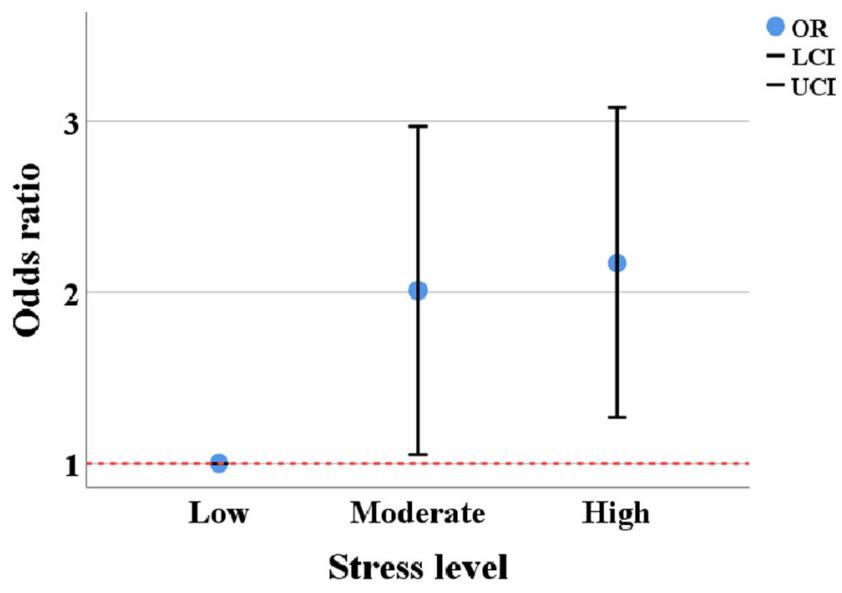

Fig. 8 Odds ratio for the risk of coronary artery disease due to traffic noise based on stress levels. The model was adjusted for age, body mass index, sleep quality, residence period, chronic disease, sensitivity, physical activity, and bedroom window orientation. OR, odds ratio; LCI, lower confidence interval; UCI, upper confidence interval

\section{Discussion}

South Asian countries have experienced nearly $75 \%$ of the healthy life years being lost due to cardiovascular diseases between 1990 and 2010 (Rehman et al. 2018). The region lacks the availability of quality data regarding the risk factors of CVDs. Studies concerned with the association of environmental stressors and CVD have remained very limited, although the research in this area has gained some momentum over the past few years. In the present
Table 5 Output for the effect modification across various levels of age group, sensitivity, stress levels, and sleep quality. The models were adjusted for age, sensitivity, stress levels, sleep quality, bedroom window orientation, chronic disease, residence period, and physical activity

\begin{tabular}{|c|c|c|c|c|}
\hline Interaction term & Odds ratio & $\begin{array}{l}\text { Lower confidence } \\
\text { interval }\end{array}$ & $\begin{array}{l}\text { Upper confidence } \\
\text { interval }\end{array}$ & $\mathrm{p}$ value \\
\hline \multicolumn{5}{|l|}{$($ Traffic noise $) \times($ Age $)$} \\
\hline Traffic noise $\times(\text { Age })_{1}{ }^{a}$ & 1.77 & 0.75 & 3.64 & 0.312 \\
\hline Traffic noise $\times(\text { Age })_{2}{ }^{\mathrm{b}}$ & 1.83 & 0.88 & 3.79 & 0.286 \\
\hline Traffic noise $\times(\text { Age })_{3}{ }^{\mathrm{c}}$ & 2.15 & 1.08 & 3.21 & 0.039 \\
\hline Traffic noise $\times(\text { Age })_{4}{ }^{\mathrm{d}}$ & 2.23 & 1.13 & 3.35 & 0.041 \\
\hline Traffic noise $\times(\text { Age })_{5}{ }^{\mathrm{e}}$ & 2.31 & 1.12 & 3.51 & 0.044 \\
\hline \multicolumn{5}{|l|}{$($ Traffic noise $) \times($ Stress $)$} \\
\hline Traffic noise $\times(\text { Stress })_{1}{ }^{\mathrm{f}}$ & 2.01 & 1.05 & 2.97 & 0.031 \\
\hline Traffic noise $\times(\text { Stress })_{2}{ }^{\mathrm{g}}$ & 2.17 & 1.27 & 3.08 & 0.025 \\
\hline \multicolumn{5}{|l|}{$($ Traffic noise $) \times($ Sleep quality $)$} \\
\hline Traffic noise $\times(\text { Sleep quality })_{1}{ }^{\mathrm{h}}$ & 2.09 & 1.08 & 3.11 & 0.016 \\
\hline Traffic noise $\times(\text { Sleep quality })_{2}{ }^{\mathrm{i}}$ & 1.51 & 0.82 & 2.40 & 0.156 \\
\hline \multicolumn{5}{|l|}{ (Traffic noise $) \times($ Sensitivity $)$} \\
\hline Traffic noise $\times(\text { Sensitivity })_{1}{ }^{j}$ & 2.25 & 1.19 & 3.32 & 0.026 \\
\hline Traffic noise $\times(\text { Sensitivity })_{2}{ }^{\mathrm{k}}$ & 2.39 & 1.22 & 3.56 & 0.029 \\
\hline
\end{tabular}




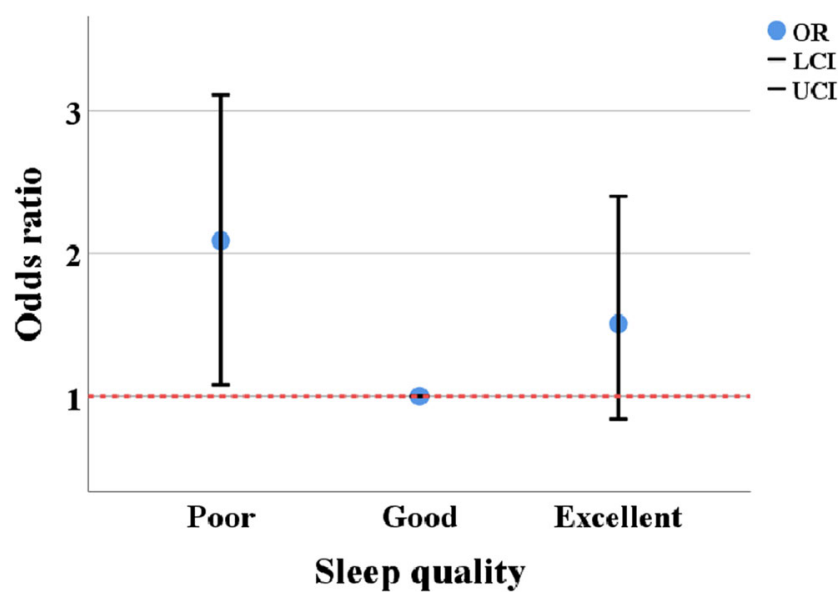

Fig. 9 Odds ratio for the risk of coronary artery disease due to traffic noise based on sleep quality. The model was adjusted for age, body mass index, stress levels, residence period, chronic disease, sensitivity, physical activity, and bedroom window orientation. OR, odds ratio; LCI, lower confidence interval; UCI, upper confidence interval

study, the assessment of the disease was based on the selfreporting about the disease and was further confirmed from the prescriptions that were requested from the respondents. This method is however in contrast to that of the European nations, where medical records of the study area residents are used for the assessment of disease. Being a rural area, medical records are not maintained both at the individual level and also at the official level. Therefore, the best possible means under the given circumstances were adopted in the study. The results from the present study suggest a threshold value of $60 \mathrm{~dB}(\mathrm{~A})$ beyond which the risk of CAD becomes significant in the adult population. The results concerning the threshold noise level reported in the study may be on the higher side given that WHO has estimated the threshold values to be around 53-55 dB(A) (Münzel et al. 2019). The study cautiously is suggestive of a linear trend for the exposure-response relation between road traffic noise levels and CAD. The study suggests a higher risk among men as compared to women which coincide with the findings of previous epidemiologic studies (Barrett-Connor 1997). The reason that can lead to such a result may be due to the higher exposure to unhealthy behavior among males like smoking, alcohol consumption, and exposure to physical hazards as compared to women (Luoto et al. 2000). Another possible reason can be the exposure to high noise levels and stressors without any control at workplaces for men as compared to women ( $\mathrm{Li}$ et al. 2019). In this part of the globe, females are mostly homemakers and thus are not exposed to higher noise levels, even though the residential building may be exposed to traffic noise but having better control in reducing the exposure can also lower the risk. Besides the attitude of males and females towards traffic noise exposure as well as the pathophysiological response to noise can also be a possible reason and thus needs further investigation (Klæboe et al. 2004; Röösli et al. 2014). Selfreporting about the prevalence of the disease can be thought to introduce bias in the study, but previous studies have shown a good correlation (kappa $=0.75$ ) between self-reported outcome disease and the actual diagnosis by a medical practitioner (Okura et al. 2004). Several studies concerning the association of road traffic noise exposure and $\mathrm{CAD}$ have been conducted but very few numbers have achieved a significant association (Babisch 2006). A meta-analysis by Babisch (2014) has shown an $8 \%$ increase in the risk for CAD among people exposed to traffic noise levels between 52 and $77 \mathrm{~dB}(\mathrm{~A})$. A study conducted in Tokyo, Japan, revealed a significant risk of 3.1 for the population exposed to traffic noise levels greater than $65 \mathrm{~dB}(\mathrm{~A})$ ) (Yoshida et al. 1997). Another study carried out in Tyrol, Austria, revealed a risk of 2.1 for people exposed to noise levels greater than 60 $\mathrm{dB}(\mathrm{A})$, which matches the results from the present study (Lercher et al. 2011).

In terms of the subgroup analysis, the study revealed an increased risk for the occurrence of CAD due to traffic noise exposure among residents reporting higher stress levels. Traffic noise has been linked with the reporting of stress in the form of anxiety and depression in many studies (Evans et al. 2001; Dzhambov and Lercher 2019; Amoatey et al. 2020). The stress-induced due to traffic noise leads to the secretion of the stress hormone cortisol in the body to maintain homeostasis. But due to continuous exposure, the stress hormones are released continuously which can prove harmful as higher stress hormone levels lead to narrowing of arteries, increase in the heart rate, blood cholesterol, and blood sugar which are the known risk factors for CAD. The study also reported a higher risk for respondents reporting poor sleep quality. As the national highway runs through the study area, there is a continuous movement of traffic, especially heavy vehicles and army vehicles during evening and nighttime. This can lead to disturbed sleep structure due to the noise produced during the movement which may, in turn, lead to a decrease in the levels of leptin (a hormone responsible for a decrease in appetite) and elevate the levels of ghrelin (a hormone responsible for an increase in appetite). This can lead to the uptake of more calories and lower energy expenditure which may result in obesity, a well-known risk factor for CAD. The reasoning is supported by other studies as well (Taheri et al. 2004; Chandola et al. 2010; Lao et al. 2018). The study also suggests higher risk with the increase in age and significant risk is reported beyond 50 years. Due to aging, there is an accumulation of damage at the tissue, cellular, and molecular levels, thereby increasing the risk for morbidity and mortality. With aging, there is a progressive deterioration of the heart and vasculature that can lead to a higher risk for the development of various cardiovascular diseases like CAD, hypertension, and myocardial infarction (Costa et al. 2015). Also being sensitive to noise, in general, increased the risk for CAD. People who are sensitive to noise usually become anxious and annoyed due to traffic noise. In response to higher levels of annoyance, maintenance of homeostasis in the body due to the release of stress hormones starts. These hormones can thus become a cause for the higher risk of CAD. 


\section{Strengths and limitations}

The study inherited the following strengths:

a) The analysis was done by stratifying the data based on gender and the risks were estimated for males and females separately. This was done because studies have found differences in the risks associated with CAD based on gender (Babisch 2006; Davies and Van Kamp 2012).

b) Effect modification across various levels of the potential mediators and confounders was performed to evaluate the risk of suffering from $\mathrm{CAD}$ due to traffic noise.

c) A threshold value for the traffic noise exposure as well as the threshold value in terms of the age of the exposed population at which the risk for CAD becomes significant was also proposed. This can prove beneficial for the health authorities as well as noise regulating authorities.

However, the study also has some associated limitations which include:

a) Traffic noise levels reaching the interiors of the residential buildings were not considered, which may have resulted in the over-estimation of the exposure levels.

b) Risk factors like blood cholesterol, blood pressure, and blood sugar which have also been found to affect the risk for occurrence for $\mathrm{CAD}$ were not taken into account.

c) Some bias might have occurred during self-reporting of the outcome disease. Some false-negative cases may have been included due to the lack of knowledge about the disease among the general population.

\section{Conclusion}

The study presents a cross-sectional design for assessing the association between road traffic noise exposure and the prevalence of CVD. The study made use of the DAG procedure for identifying the minimal set of covariates that needed to be adjusted so that unbiased direct effects of traffic noise on CAD could be obtained. Concerning the primary objective of the study, a significant association was found between traffic noise exposure and the prevalence of CAD with higher risks for noisy areas as compared to quiet areas. The study suggests that traffic noise exposure (expressed as $\left.\mathrm{L}_{\mathrm{den}}\right)>60 \mathrm{~dB}(\mathrm{~A})$ is significantly associated with the prevalence of CAD. The subgroup analysis in terms of gender revealed that males were having higher risks as compared to females. In terms of personal characteristics like age, the threshold range varied from 50 to 59 years, while in terms of sleep quality, poor sleep quality was having significantly higher risk as compared to the reference groups. In terms of the stress level, both moderate and higher levels of stress were found to have higher risks as compared to the lower levels of stress. Being sensitive to noise also revealed a higher risk for the prevalence of CAD as compared to the non-sensitive population. The results from the study should be used after giving due consideration to the limitations mentioned, the inclusion of respondents greater than 18 years, and the overall sociodemographic, environmental, geographical conditions, and lifestyle of the study area before comparing with any other study.

Supplementary Information The online version contains supplementary material available at https://doi.org/10.1007/s11356-021-14582-2.

Acknowledgments The authors would like to thank the Traffic and Transportation Planning Section of the Department of Civil Engineering, NIT Srinagar, for providing the necessary logistics for conducting the study. We express a deep sense of gratitude to Dr. Mohammad Azhar Gilani for helping in verifying the medical reports obtained from the respondents with the disease, especially during the ongoing coronavirus (COVID-19) pandemic. The authors would also like to thank the esteemed reviewers for their valuable suggestions for the improvement of the manuscript.

Availability of data and materials The datasets generated during the current study are not publicly available due to their usage in another study, which is part of the research work currently in progress, but is available from the corresponding author on reasonable request.

Authors' contribution TAG was associated with data collection, noise modeling, and article preparation work. MSM was associated with the review and correction process. All the authors read and approved the final manuscript.

\section{Declarations}

Ethics approval The study was approved by the ethical committee at NIT Srinagar.

Consent to participate Verbal consent was taken from each respondent during the survey.

Consent for publication Not applicable.

Competing interests The authors declare that they have no competing interests.

\section{References}

Amoatey P, Omidvarbona H, Bawain MS, al-Mayahi A, al-Mamun A, al-Harthy I (2020) Exposure assessment to road traffic noise levels and health effects in an arid urban area. Environ Sci Pollut Res Int 27:35051-35064. https://doi.org/10.1007/s11356-020-09785-y 
Appelman Y, van Rijn BB, Ten Haaf ME et al (2015) Sex differences in cardiovascular risk factors and disease prevention. Atherosclerosis 241:211-218. https://doi.org/10.1016/j.atherosclerosis.2015.01.027

Appelros P, Stegmayr B, Terént A (2009) Sex differences in stroke epidemiology: a systematic review. Stroke 40:1082-1090. https://doi. org/10.1161/STROKEAHA.108.540781

Aronson D, Rayfield EJ (2002) How hyperglycemia promotes atherosclerosis: molecular mechanisms. Cardiovasc Diabetol 1:1. https://doi. org/10.1186/1475-2840-1-1

Austin AE, Desrosiers TA, Shanahan ME (2019) Directed acyclic graphs: An under-utilized tool for child maltreatment research. Child Abuse Negl 91:78-87. https://doi.org/10.1016/j.chiabu.2019.02.011

Babisch W (2003) Stress hormones in the research on cardiovascular effects of noise. Noise Health 5:1-11

Babisch W (2006) Transportation noise and cardiovascular risk: updated review and synthesis of epidemiological studies indicate that the evidence has increased. Noise Health 8:1-29. https://doi.org/10. 4103/1463-1741.32464

Babisch W (2011) Cardiovascular effects of noise. Noise Health 13:201204. https://doi.org/10.4103/1463-1741.80148

Babisch W (2014) Updated exposure-response relationship between road traffic noise and coronary heart diseases: a meta-analysis. Noise Heal 16:1-9. https://doi.org/10.4103/1463-1741.127847

Babisch W, van Kamp I (2009) Exposure-response relationship of the association between aircraft noise and the risk of hypertension. Noise Health 11:161-168. https://doi.org/10.4103/1463-1741. 53363

Babisch W, Ising H, Gallacher JEJ (2003) Health status as a potential effect modifier of the relation between noise annoyance and incidence of ischaemic heart disease. Occup Environ Med 60:739-745. https://doi.org/10.1136/oem.60.10.739

Banerjee D, Chakraborty S, Bhattacharyya S, Gangopadhyay A (2008) Evaluation and analysis of road traffic noise in Asansol: an industrial town of Eastern India. Int J Environ Res Public Health 5:165-171. https://doi.org/10.3390/ijerph5030165

Banerjee D, Das PP, Fouzdar A (2014) Urban residential road traffic noise and hypertension: a cross-sectional study of adult population. J Urban Health 91:1144-1157. https://doi.org/10.1007/s11524-0149916-1

Barregard L, Bonde E, Ohrström E (2009) Risk of hypertension from exposure to road traffic noise in a population-based sample. Occup Environ Med 66:410-415. https://doi.org/10.1136/oem.2008. 042804

Barrett-Connor E (1997) Sex differences in coronary heart disease: why are women so superior? The 1995 Ancel Keys Lecture. Circulation 95:252-264. https://doi.org/10.1161/01.CIR.95.1.252

Basner M, Müller U, Elmenhorst E-M (2011) Single and combined effects of air, road, and rail traffic noise on sleep and recuperation. Sleep 34:11-23. https://doi.org/10.1093/sleep/34.1.11

Basner M, Babisch W, Davis A, Brink M, Clark C, Janssen S, Stansfeld S (2014) Auditory and non-auditory effects of noise on health. Lancet 383:1325-1332. https://doi.org/10.1016/S0140-6736(13)61613-X

Begou P, Kassomenos P (2020) Exposure to the road traffic noise in an urban complex in Greece: the quantification of healthy life years lost due to noise-induced annoyance and noise-induced sleep disturbances. Environ Sci Pollut Res 28:12932-12943. https://doi.org/ 10.1007/s11356-020-11190-4

Belojevic, Saric-Tanaskovic (2002) Prevalence of arterial hypertension and myocardial infarction in relation to subjective ratings of traffic noise exposure. Noise Health 4:33-37

Belojevic G, Paunovic K, Jakovljevic B, Stojanov V, Ilic J, Slepcevic V, Saric-Tanaskovic M (2011) Cardiovascular effects of environmental noise: research in Serbia. Noise Health 13:217-220

Benjamin EJ, Muntner P, Alonso A, Bittencourt MS, Callaway CW, Carson AP, Chamberlain AM, Chang AR, Cheng S, Das SR, Delling FN, Djousse L, Elkind MSV, Ferguson JF, Fornage M,
Jordan LC, Khan SS, Kissela BM, Knutson KL, Kwan TW, Lackland DT, Lewis TT, Lichtman JH, Longenecker CT, Loop MS, Lutsey PL, Martin SS, Matsushita K, Moran AE, Mussolino ME, O'Flaherty M, Pandey A, Perak AM, Rosamond WD, Roth GA, Sampson UKA, Satou GM, Schroeder EB, Shah SH, Spartano NL, Stokes A, Tirschwell DL, Tsao CW, Turakhia MP, VanWagner LB, Wilkins JT, Wong SS, Virani SS, On behalf of the American Heart Association Council on Epidemiology and Prevention Statistics Committee and Stroke Statistics Subcommittee (2019) Heart Disease and Stroke Statistics-2019 Update: a Report From the American Heart Association. Circulation 139:e56-e528. https://doi.org/10.1161/CIR. 0000000000000659

Berglund B, Lindvall T (n.d.) DHS Guidelines for community noise. World Health Organization

Beutel ME, Junger C, Klein EM et al (2016) Noise annoyance is associated with depression and anxiety in the general population- the contribution of aircraft noise. PLoS One 11:e0155357. https://doi.org/ 10.1371/journal.pone. 0155357

Bluhm G, Nordling E, Berglind N (2019) Road traffic noise and annoyance-an increasing environmental health problem. Noise Health 6:43-49

Bodin T, Albin M, Ardö J, Stroh E, Östergren PO, Björk J (2009) Road traffic noise and hypertension: results from a cross-sectional public health survey in southern Sweden. Environ Health 8:38. https://doi. org/10.1186/1476-069X-8-38

Brink M, Schäffer B, Vienneau D, Foraster M, Pieren R, Eze IC, Cajochen C, Probst-Hensch N, Röösli M, Wunderli JM (2019) A survey on exposure-response relationships for road, rail, and aircraft noise annoyance: differences between continuous and intermittent noise. Environ Int 125:277-290. https://doi.org/10.1016/j.envint. 2019.01 .043

Brown AL (2015) Effects of road traffic noise on health: from burden of disease to effectiveness of interventions. Procedia Environ Sci 30:39. https://doi.org/10.1016/j.proenv.2015.10.001

Carter N, Henderson R, Lal S, Hart M, Booth S, Hunyor S (2002) Cardiovascular and autonomic response to environmental noise during sleep in night shift workers. Sleep 25:444-451. https://doi.org/ 10.1093/sleep/25.4.444

Chandola T, Ferrie JE, Perski A, Akbaraly T, Marmot MG (2010) The effect of short sleep duration on coronary heart disease risk is greatest among those with sleep disturbance: a prospective study from the Whitehall II Cohort. Sleep 33:739-744. https://doi.org/ 10.1093/sleep/33.6.739

Chang T-Y, Lai Y-A, Hsieh H-H, Lai JS, Liu CS (2009) Effects of environmental noise exposure on ambulatory blood pressure in young adults. Environ Res 109:900-905. https://doi.org/10.1016/j. envres.2009.05.008

Chao AM, Jastreboff AM, White MA, Grilo CM, Sinha R (2017) Stress, cortisol, and other appetite-related hormones: prospective prediction of 6-month changes in food cravings and weight. Obesity (Silver Spring) 25:713-720. https://doi.org/10.1002/oby.21790

Charakida M, Deanfield JE (2013) Nighttime aircraft noise exposure: flying towards arterial disease. Eur Heart J 34:3472-3474. https:// doi.org/10.1093/eurheartj/eht339

Cohen S, Kamarck T, Mermelstein R (1983) A global measure of perceived stress. J Health Soc Behav 24:385-396. https://doi.org/10. 2307/2136404

Cohen AJ, Brauer M, Burnett R, Anderson HR, Frostad J, Estep K, Balakrishnan K, Brunekreef B, Dandona L, Dandona R, Feigin V, Freedman G, Hubbell B, Jobling A, Kan H, Knibbs L, Liu Y, Martin R, Morawska L, Pope CA III, Shin H, Straif K, Shaddick G, Thomas M, van Dingenen R, van Donkelaar A, Vos T, Murray CJL, Forouzanfar MH (2017) Estimates and 25-year trends of the global burden of disease attributable to ambient air pollution: an analysis of 
data from the Global Burden of Diseases Study 2015. Lancet 389: 1907-1918. https://doi.org/10.1016/S0140-6736(17)30505-6

Costa E, Santos-Silva A, Paúl C, González Gallego J (2015) Aging and cardiovascular risk. Biomed Res Int 2015:871656-871652. https:// doi.org/10.1155/2015/871656

Datta JK, Sadhu S, Gupta S, Saha R, Mondal NK, Mukhopadhyay B (2006) Assessment of noise level in Burdwan town, West Bengal. J Environ Biol 27:609-612

Davies H, Van Kamp I (2012) Noise and cardiovascular disease: a review of the literature 2008-2011. Noise Health 14:287-291. https://doi. org/10.4103/1463-1741.104895

de Kluizenaar Y, Gansevoort RT, Miedema HME, de Jong PE (2007) Hypertension and road traffic noise exposure. J Occup Environ Med 49:484-492. https://doi.org/10.1097/JOM.0b013e318058a9ff

Di Giosia P, Passacquale G, Petrarca M et al (2017) Gender differences in cardiovascular prophylaxis: focus on antiplatelet treatment. Pharmacol Res 119:36-47. https://doi.org/10.1016/j.phrs.2017.01. 025

Dzhambov AM, Lercher P (2019) Road traffic noise exposure and depression/anxiety: an updated systematic review and meta-analysis. Int J Environ Res Public Health 16:4134

Ebong IA, Goff DC, Rodriguez CJ et al (2014) Mechanisms of heart failure in obesity. Obes Res Clin Pract 8:e540-e548. https://doi. org/10.1016/j.orcp.2013.12.005

Evans GW, Lercher P, Meis M, Ising H, Kofler WW (2001) Community noise exposure and stress in children. J Acoust Soc Am 109:10231027. https://doi.org/10.1121/1.1340642

Gan WQ, Davies HW, Demers PA (2011) Exposure to occupational noise and cardiovascular disease in the United States: the National Health and Nutrition Examination Survey 1999-2004. Occup Environ Med 68:183-190. https://doi.org/10.1136/oem.2010. 055269

Gao Z, Chen Z, Sun A, Deng X (2019) Gender differences in cardiovascular disease. Med Nov Technol Devices 4:100025. https://doi.org/ 10.1016/j.medntd.2019.100025

Goswami S, Nayak SK, Pradhan AC, Dey SK (2011) A study on traffic noise of two campuses of University, Balasore, India. J Environ Biol 32:105-109

Griefahn B, Bröde P, Marks A, Basner M (2008) Autonomic arousals related to traffic noise during sleep. Sleep 31:569-577. https://doi. org $/ 10.1093 /$ sleep $/ 31.4 .569$

Héritier H, Vienneau D, Foraster M et al (2017) Transportation noise exposure and cardiovascular mortality: a nationwide cohort study from Switzerland. Eur J Epidemiol 32:307-315. https://doi.org/10. 1007/s10654-017-0234-2

Hochman JS, Tamis JE, Thompson TD, Weaver WD, White HD, van de Werf F, Aylward P, Topol EJ, Califf RM (1999) Sex, clinical presentation, and outcome in patients with acute coronary syndromes. Global Use of Strategies to Open Occluded Coronary Arteries in Acute Coronary Syndromes IIb Investigators. N Engl J Med 341: 226-232. https://doi.org/10.1056/NEJM199907223410402

IHME (2010) Global Burden of Disease (GBD) | Institute for Health Metrics and Evaluation. http://www.healthdata.org/sites/default/ files/files/country_profiles/GBD/ihme_gbd_country_report_india. Accessed 21 Dec 2020

Jarup L, Babisch W, Houthuijs D, Pershagen G, Katsouyanni K, Cadum E, Dudley ML, Savigny P, Seiffert I, Swart W, Breugelmans O, Bluhm G, Selander J, Haralabidis A, Dimakopoulou K, Sourtzi P, Velonakis M, Vigna-Taglianti F, HYENA study team (2008) Hypertension and exposure to noise near airports: the HYENA Study. Environ Health Perspect 116:329-333. https://doi.org/10. 1289/ehp. 10775

Kalsch H, Hennig F, Moebus S, Mohlenkamp S, Dragano N, Jakobs H, Memmesheimer M, Erbel R, Jockel KH, Hoffmann B, on behalf of the Heinz Nixdorf Recall Study Investigative Group, Roggenbuck U, Slomiany U, Beck EM, Offner A, Munkel S, Schrader S, Peter R,
Hirche H, Meinertz T, Bode C, deFeyter PJ, Guntert B, Halli T, Gutzwiller F, Heinen H, Hess O, Klein B, Lowel H, Reiser M, Schmidt G, Schwaiger M, Steinmuller C, Theorell T, Willich SN (2014) Are air pollution and traffic noise independently associated with atherosclerosis: the Heinz Nixdorf Recall Study. Eur Heart J 35:853-860. https://doi.org/10.1093/eurheartj/eht426

Kelli HM, Mehta A, Tahhan AS, Liu C, Kim JH, Dong TA, Dhindsa DS, Ghazzal B, Choudhary MK, Sandesara PB, Hayek SS, Topel ML, Alkhoder AA, Martini MA, Sidoti A, Ko YA, Lewis TT, Vaccarino V, Sperling LS, Quyyumi AA (2019) Low educational attainment is a predictor of adverse outcomes in patients with coronary artery disease. J Am Heart Assoc 8:e013165. https://doi.org/10.1161/ JAHA.119.013165

Klæboe R, Amundsen A, Fyhri A, Solberg S (2004) Road traffic noise the relationship between noise exposure and noise annoyance in Norway. Appl Acoust 65:893-912. https://doi.org/10.1016/j. apacoust.2004.04.001

Ko JH, Chang SI, Lee BC (2011) Noise impact assessment by utilizing noise map and GIS: a case study in the city of Chungju, Republic of Korea. Appl Acoust 72:544-550. https://doi.org/10.1016/j. apacoust.2010.09.002

Lao XQ, Liu X, Deng HB, Chan TC, Ho KF, Wang F, Vermeulen R, Tam T, Wong MCS, Tse LA, Chang LY, Yeoh EK (2018) Sleep quality, sleep duration, and the risk of coronary heart disease: a prospective cohort study with 60, 586 adults. J Clin Sleep Med 14: 109-117. https://doi.org/10.5664/jcsm.6894

Leon Bluhm G, Berglind N, Nordling E, Rosenlund M (2006) Road traffic noise and hypertension. Occup Environ Med 64:122-126. https://doi.org/10.1136/oem.2005.025866

Lercher P, Botteldooren D, Widmann U, Uhrner U, Kammeringer E (2011) Cardiovascular effects of environmental noise: research in Austria. Noise Health 13:234-250

Lerner DJ, Kannel WB (1986) Patterns of coronary heart disease morbidity and mortality in the sexes: a 26-year follow-up of the Framingham population. Am Heart J 111:383-390. https://doi.org/ 10.1016/0002-8703(86)90155-9

Li X, Dong Q, Wang B, Song H, Wang S, Zhu B (2019) The influence of occupational noise exposure on cardiovascular and hearing conditions among industrial workers. Sci Rep 9:11524. https://doi.org/10. 1038/s41598-019-47901-2

Luoto R, Uutela A, Puska P (2000) Occasional smoking increases total and cardiovascular mortality among men. Nicotine Tob Res 2:133139. https://doi.org/10.1080/713688127

Manzar MD, Moiz JA, Zannat W et al (2015) Validity of the Pittsburgh Sleep Quality Index in Indian University Students. Oman Med J 30: 193-202. https://doi.org/10.5001/omj.2015.41

Munzel T, Gori T, Babisch W, Basner M (2014) Cardiovascular effects of environmental noise exposure. Eur Heart J 35:829-836. https://doi. org/10.1093/eurheartj/ehu030

Münzel T, Sørensen M, Schmidt F, Schmidt E, Steven S, Kröller-Schön S, Daiber A (2018) The adverse effects of environmental noise exposure on oxidative stress and cardiovascular risk. Antioxid Redox Signal 28:873-908. https://doi.org/10.1089/ars.2017.7118

Münzel T, Kröller-Schön S, Oelze M et al (2019) Adverse cardiovascular effects of traffic noise with a focus on nighttime noise and the new WHO noise guidelines. Annu. Rev. Public Health 41:309-328

Okura Y, Urban LH, Mahoney DW, Jacobsen SJ, Rodeheffer RJ (2004) Agreement between self-report questionnaires and medical record data was substantial for diabetes, hypertension, myocardial infarction and stroke but not for heart failure. J Clin Epidemiol 57:10961103. https://doi.org/10.1016/j.jclinepi.2004.04.005

Pangtey R, Basu S, Meena GS, Banerjee B (2020) Perceived stress and its epidemiological and behavioral correlates in an urban area of Delhi, India: a community-based cross-sectional study. Indian J Psychol Med 42:80-86. https://doi.org/10.4103/IJPSYM.IJPSYM_528_18 
Pathak V, Tripathi BD, Kumar MV (2008) Evaluation of traffic noise pollution and attitudes of exposed individuals in working place. Atmos Environ 42:3892-3898. https://doi.org/10.1016/j.atmosenv. 2007.12.070

Pucher J, Korattyswaropam N, Mittal N, Ittyerah N (2005) Urban transport crisis in India. Transp Policy 12:185-198. https://doi.org/10. 1016/j.tranpol.2005.02.008

Rashid S, Khandaker N (2007) Risk Factors for Early Myocardial Infarction in South Asians. JAMA 297:1880-1; author reply 1881. https://doi.org/10.1001/jama.297.17.1880-b

Reddy S, Balachandra P (2010) Dynamics of urban mobility : a comparative analysis of megacities of India

Rehman H, Samad Z, Mishra SR, Merchant AT, Narula JP, Mishra S, Virani SS (2018) Epidemiologic studies targeting primary cardiovascular disease prevention in South Asia. Indian Heart J 70:721730. https://doi.org/10.1016/j.ihj.2018.01.029

Röösli M, Vienneau D, Frei P, Mohler E (2014) Noise-related sleep disturbances: does gender matter? Noise Health 16:197-204. https://doi.org/10.4103/1463-1741.137036

Rubin JB, Borden WB (2012) Coronary heart disease in young adults. Curr Atheroscler Rep 14:140-149. https://doi.org/10.1007/s11883012-0226-3

Sattar N, Greer IA (2002) Pregnancy complications and maternal cardiovascular risk: opportunities for intervention and screening? BMJ 325:157-160. https://doi.org/10.1136/bmj.325.7356.157

Schmidt FP, Basner M, Kroger G, Weck S, Schnorbus B, Muttray A, Sariyar M, Binder H, Gori T, Warnholtz A, Munzel T (2013) Effect of nighttime aircraft noise exposure on endothelial function and stress hormone release in healthy adults. Eur Heart J 34:35083514. https://doi.org/10.1093/eurheartj/eht269

Schmidt F, Kolle K, Kreuder K, Schnorbus B, Wild P, Hechtner M, Binder H, Gori T, Münzel T (2015) Nighttime aircraft noise impairs endothelial function and increases blood pressure in patients with or at high risk for coronary artery disease. Clin Res Cardiol 104:23-30. https://doi.org/10.1007/s00392-014-0751-x

Selander J, Nilsson ME, Bluhm G, Rosenlund M, Lindqvist M, Nise G, Pershagen G (2009) Long-term exposure to road traffic noise and myocardial infarction. Epidemiology 20:272-279. https://doi.org/ 10.1097/EDE.0b013e31819463bd

Shrier I, Platt RW (2008) Reducing bias through directed acyclic graphs. BMC Med Res Methodol 8:70. https://doi.org/10.1186/1471-2288$8-70$

Shukla AK, Jain SS, Parida M, Srivastava JB (2009) Performance of FHWA model for predicting traffic noise: a case study of Metropolitan city, Lucknow (India). Transport 24:234-240. https://doi.org/10.3846/1648-4142.2009.24.234-240

Smyth C (2002) The Pittsburgh Sleep Quality Index. Geriatr Nurs (Minneap) 23:56. https://doi.org/10.1016/S0197-4572(02)70029-3

Sorensen M, Hvidberg M, Andersen ZJ, Nordsborg RB, Lillelund KG, Jakobsen J, Tjonneland A, Overvad K, Raaschou-Nielsen O (2011) Road traffic noise and stroke: a prospective cohort study. Eur Heart J 32:737-744. https://doi.org/10.1093/eurheartj/ehq466
Srinath Reddy K, Shah B, Varghese C, Ramadoss A (2005) Responding to the threat of chronic diseases in India. Lancet 366:1744-1749. https://doi.org/10.1016/S0140-6736(05)67343-6

Stansfeld SA, Shipley M (2015) Noise sensitivity and future risk of illness and mortality. Sci Total Environ 520:114-119. https://doi.org/10. 1016/j.scitotenv.2015.03.053

Sygna K, Aasvang GM, Aamodt G, Oftedal B, Krog NH (2014) Road traffic noise, sleep and mental health. Environ Res 131:17-24. https://doi.org/10.1016/j.envres.2014.02.010

Taheri S, Lin L, Austin D, Young T, Mignot E (2004) Short sleep duration is associated with reduced leptin, elevated ghrelin, and increased body mass index. PLoS Med 1:e62. https://doi.org/10. 1371/journal.pmed.0010062

Textor J, Hardt J, Knüppel S (2011) DAGitty: a graphical tool for analyzing causal diagrams. Epidemiology 22:745. https://doi.org/10. 1097/EDE.0b013e318225c2be

Tobías A, Recio A, Díaz J, Linares C (2015) Noise levels and cardiovascular mortality: a case-crossover analysis. Eur J Prev Cardiol 22: 496-502. https://doi.org/10.1177/2047487314528108

van Kempen E, Casas M, Pershagen G, Foraster M (2018) WHO Environmental Noise Guidelines for the European Region: A systematic review on environmental noise and cardiovascular and metabolic effects: a summary. Int J Environ Res Public Health 15:379. https://doi.org/10.3390/ijerph15020379

WHO (2011) Burden of disease from environmental noise : quantification of healthy life years lost in Europe. The WHO European Centre for Environment and Health, Bonn Office, WHO Regional Office, Copenhagen

Winzer EB, Woitek F, Linke A (2018) Physical activity in the prevention and treatment of coronary artery disease. J Am Heart Assoc 7:1-15. https://doi.org/10.1161/JAHA.117.007725

Wouk K, Bauer AE, Gottfredson NC (2019) How to implement directed acyclic graphs to reduce bias in addiction research. Addict Behav 94:109-116. https://doi.org/10.1016/j.addbeh.2018.09.032

Writing Group Members, Mozaffarian D, Benjamin EJ et al (2016) Heart Disease and Stroke Statistics-2016 Update: a Report From the American Heart Association. Circulation 133:e38-e360. https:// doi.org/10.1161/CIR.0000000000000350

Yoshida T, Osada Y, Kawaguchi T, Hoshiyama Y, Yoshida K, Yamamoto K (1997) Effects of road traffic noise on inhabitants of Tokyo. J Sound Vib 205:517-522. https://doi.org/10.1006/jsvi. 1997.1020

Zare Sakhvidi MJ, Zare Sakhvidi F, Mehrparvar AH, Foraster M, Dadvand P (2018) Association between noise exposure and diabetes: a systematic review and meta-analysis. Environ Res 166:647657. https://doi.org/10.1016/j.envres.2018.05.011

Publisher's note Springer Nature remains neutral with regard to jurisdictional claims in published maps and institutional affiliations. 